\title{
Study on in-Situ Stress Distribution in the East and West of Sichuan Basin
}

\section{Xinxin Fang ( $\sim$ fx15827573109@163.com )}

China Coal Research Institute

\section{Hong Feng}

China Coal Technology and Engineering Group Xian Institute

\section{Research Letter}

Keywords: In-situ stress, Sichuan Basin, Distribution law, Maximum horizontal principal stress, Minimum horizontal principal stress, Vertical principal stress

Posted Date: May 10th, 2021

DOI: https://doi.org/10.21203/rs.3.rs-482691/v1

License: (c) (1) This work is licensed under a Creative Commons Attribution 4.0 International License. Read Full License 


\section{Study on in-situ stress distribution in the east and west of Sichuan basin}

FANG Xinxin $* 1,2$, FENG Hong ${ }^{2}$

1. China Coal Research Institute, Beijing 100013;

2. China Coal Technology \& Engineering Group Xian Institute, Xian 710077, Shanxi, China)

Abstract: This paper statistically analyzed 112 acoustic emission experimental data of cores from 38 wells in the Upper Permian Changxing Formation, Triassic Xujiahe Formation, Leikoupo Formation, Jialingjiang Formation, and Feixianguan Formation in the northeastern Sichuan Basin, and 106 acoustic emission test data of cores from 32 wells of the Jurassic Shaximiao Formation and Penglai Formation in western Sichuan, eliminated data with large errors, established scatter plots of in-situ stress changing with depth in northeastern and western Sichuan, and carried out corresponding regression analysis. Studies show that the in-situ stress distribution rules in northeastern Sichuan and western Sichuan are quite different, which are mainly related to the evolution and tectonic movement of basin. The vertical stress of two blocks is generally linear with the depth, and the vertical stress value is related to the rock. The difference between overburden weight and vertical stress is small. The maximum and minimum horizontal principal stresses gradually increase with buried depth, and the degree that horizontal principal stress increase with buried depth in northeastern Sichuan is generally greater than that in western Sichuan. The horizontal shear stress is also linear with buried depth. The corresponding linear relationship is stronger in the western part of Sichuan, while the dispersion in the eastern part of Sichuan has an increasing trend as the buried depth increases. The elastic modulus of rock directly affects stress value of rock. Generally, the higher the elastic modulus of rock, the better it is to maintain higher stress. The elastic modulus of rocks of different genesis is obviously different, and the relationship between the stress value of rock and the elastic modulus is quite different. Because strength of carbonate rock is greater than that of sandstone, the change of elastic modulus is the maximum level of carbonate rock. The influence of principal stress is greater than that of sandstone, and the influence of minimum principal stress of sandstone is greater than that of carbonate rock. In carbonate rock, the effect of elastic modulus on the minimum horizontal principal stress is greater than the maximum horizontal principal stress, while in sandstone it is the opposite.

Keywords: In-situ stress; Sichuan Basin; Distribution law; Maximum horizontal principal stress; Minimum horizontal principal stress; Vertical principal stress

\section{Introduction}

In-situ stress is formed under the action of geological tectonic movement and rock mass gravity. After in-situ stress is formed, it is affected by local factors and changes, making its distribution complicated ${ }^{[1]}$. Practice shows that in-situ stress has an important influence on oil and gas exploration and production, drilling operations, and wellbore stability. Especially for the Sichuan Basin, tectonic movement is relatively violent, and there are many stress concentration areas, which seriously affect drilling operations and exploitation of tight gas reservoirs. Natural gas reservoirs with carbonate rock and tight sandstone as reservoirs have small pores and thin throats. In most ${ }^{1}$ cases, fracturing is required for efficient mining. In-situ stress is an extremely important parameter

*Correspondence: fx15827573109@163.com

China Coal Research Institute, Beijing. China Coal Technology \& Engineering Group Xian Institute, Xian 
in fracturing operations, which determines the entire fracturing process, especially in the Sichuan Basin, which is rich in natural gas, and the current distribution of in-situ stress in the entire basin. The characteristics have not been studied in detail. Therefore, it is extremely necessary to deeply study the distribution law of in-situ stress in the Sichuan Basin.

In the process of studying the distribution of in-situ stress, scholars have found that there are many factors that affect the in-situ stress. Cai Meifeng (1997) found that the maximum principal stress has a certain linear relationship with the nature of the surrounding rock by studying the relationship between the in-situ stress of the mine and the surrounding rock ${ }^{[2]}$. Zhan Fenglin (2006) found that the temperature stress caused by the same geothermal gradient in different rocks is very different. It is believed that the influence of geothermal gradient on rock stress distribution cannot be ignored [3]. Jing Feng (2008) studied the characteristics of in-situ stress distribution in the shallow crust of China's earth, and proposed that geological origin was an important factor in the difference in insitu stress distribution [4]. Pei Qitao (2016) combined with the theory of elasticity to derive the quantitative relationship between horizontal principal stress and rock mass property parameters ${ }^{[5]}$. Kang Hongpu (2010) studied the distribution of in-situ stress in coal mines with different tectonic backgrounds in China and found that the type of structure has an impact on the magnitude and direction of the in-situ stress ${ }^{[6]}$. Brady and Brown research found that terrain, structure, and erosion affect the in-situ stress state ${ }^{[7]}$. Hudson believes that high-level stress is caused by a combination of factors such as erosion, tectonics, and rock anisotropy ${ }^{[8]}$.

At present, Chinese scholars mostly refer to the method of Brown \& Hoek (1978) in studying the distribution of in-situ stress. These two scholars have conducted deep research on in-situ stress in the world, which has certain reference significance for engineering construction and shallow mineral resource development. According to Brown\&Hoek's research ideas, Chinese scholars Zhao Dean, Jing Feng, Zhu Huanchun, Kang Hongpu and other scholars have done research on the distribution of in-situ stress in China's shallow formations, and established an in-situ stress database ${ }^{[9-12]}$. The results of these studies show that the ratio of the horizontal stress to vertical stress measured in China is greater than the stress level of the Brown-Hoek envelope, while the maximum stress envelope is basically consistent with the Brown-Hoek envelope, and the minimum stress envelope is smaller than the Brown-Hoek envelope. The stress level of the covered wire. Although these scholars have achieved certain results in the research on the distribution of in-situ stress in China, these research results are mainly applicable to the shallow crust with a buried depth of less than 300 meters, and are not applicable to the deep stratum in the Sichuan Basin. At present, it is applicable to the in-situ stress in the Sichuan Basin. The law of distribution has not been systematically studied. In this paper, a total of more than 300 measured data of in-situ stress in the Puguang gas field and Yuanba gas field in northeastern Sichuan and the Xinchang, Dongtai and Luodai gas fields in western Sichuan are selected. Fracturing method. The distribution figures of vertical and horizontal in-situ stress with depth in northeastern Sichuan and western Sichuan are established, the characteristics of horizontal shear stress and lateral pressure coefficient varying with depth are studied, and the influence of rock mechanical parameters on stress is discussed.

\section{Geological setting}

The Sichuan Basin, which belongs to the Yangzi quasi-platform in the Sichuan Basin, has begun to develop a stable platform since the Jinning Movement and Chengjiang Movement returned to the basement and consolidated. The Paleozoic period was relatively uplifted. Historically, the Sichuan 
Basin has experienced frequent ups and downs. However, since the Sinian, the whole stratum has been mainly submerged and accepted by sedimentation. The entire stratum lacks the Devonian and Carboniferous, and is about $12,000 \mathrm{~m}$ thick. The Indosinian movement turned into a large depression, and folds and uplifts appeared after the Late Yanshan Movement, especially the Himalayas. The pattern of basin is mainly controlled by two structural lines northeast-southwest and northwest, forming a typical rhomboid basin. The sedimentary evolution process of the entire Sichuan Basin includes the platform deposition stage dominated by marine carbonate rock and the basin deposition stage dominated by continental clastic rock. The lithology of the marine carbonate rock formation is limestone and dolomite. The lithology of rock, gypsum, and terrigenous clastic rock is sand and mudstone (Figure 2). After the Middle Triassic, due to plate collision and fusion, the Upper Yangtze Sea gradually closed, and the marine sedimentary history of the Sichuan Basin came to an end, and the Sichuan Tectonic Basin was gradually formed. Entering the stage of continental deposition in foreland basins and depressions, nearly $6000 \mathrm{~m}$ of lacustrine deposits have developed from the Jurassic to the Cretaceous (Figure 1).

The northwest of the Sichuan Basin is the Longmenshan platform margin fault fold belt, which transitions outward to the Songpan-Garzi geosynclinal folded system. The northeast side is the Dabashan platform margin fault fold belt, which transitions outward to the Qinling geosynclinal folded system. Southeast and southwest one the side is the Yunnan-Qianchuan-E platform fold belt. The basin has an obvious rhombus shape and is roughly distributed northeast, which reflects that the evolution of deep faults in the Yangtze platform controlled the formation of the Sichuan Basin and the generation, development, and distribution of folds in the basin (Figure 1).

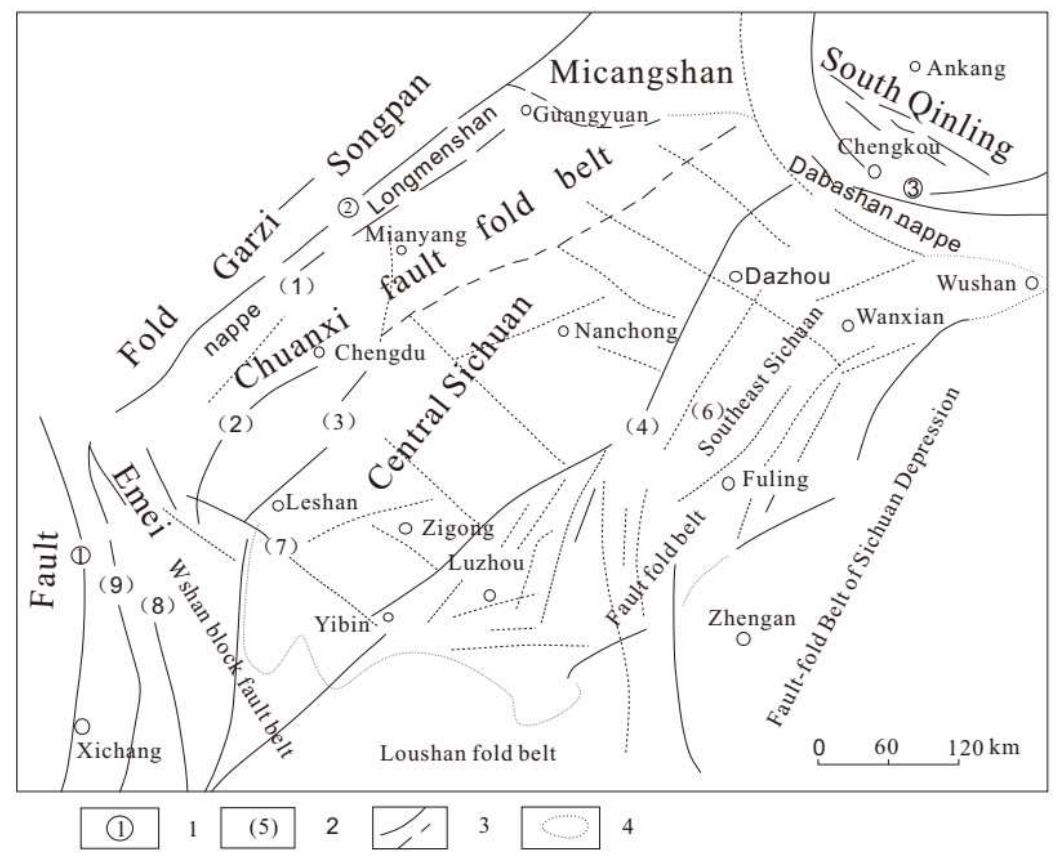

1. Deep and large lithospheric faults: (1)Anning River, (2)Longmen Mountain, (3)Chengkou, (4) Qiyao Mountain;

2. Deep and large crustal faults: (1) Peng Guan, (2) Xiongpo, (3) Long Quan Mountain, (4) Huaying Mountain, (5) Wuxi-Tiexi, (6) Huangnitang, (7) Emei-Washan, (8) Ganluo-Xiaojiang, (9) PuxiongPudu River;

3. Large deep faults in the caprock (including basement faults); 4. Basin scope

Figure1: Regional structural map of Sichuan Basin (Adapted from Yang Zhibin, 2011) 


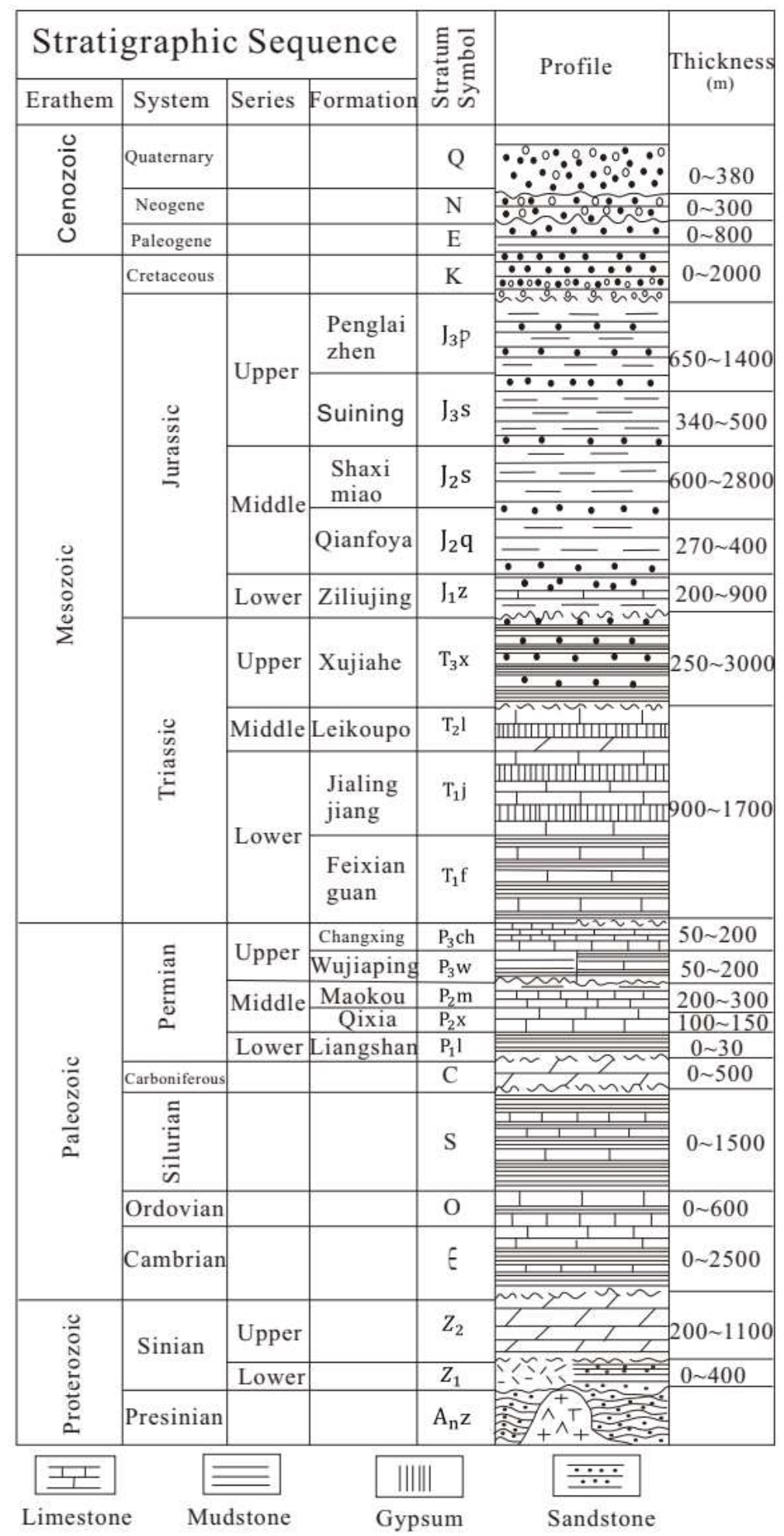

Figure2: Comprehensive histogram of Sichuan Basin strata (Adapted from Yang Zhibin, 2011)

\section{Methods and Data}

In this paper, Most of the rock mechanics experiments were conducted in the State Key Laboratory of "Oil and Gas Reservoir Geology and Development Engineering" of Chengdu University of Technology using "MTS Rock Physics Parameter Test System", and the "State Key Laboratory of Geological Hazard Prevention and Environmental Protection" of Chengdu University of 
Technology using American products MTS 815 programmable servo rigidity testing machine and AE-21C acoustic emission detection system produced by Shenyang Computer Research Institute. Some experiments were completed in the Institute of Geomechanics of the Chinese Academy of Geological Sciences by German-200 pressure testing machine and American vertical 2G-755R superconducting magnetometer.

This paper systematically carried out the rock mechanics experiment in the Sichuan Basin. Among them, continental clastic rock samples are the cores of Well X203 and X209, well section is 2100$3300 \mathrm{~m}$, and the layers are Shaximiao Formation, Qianfoya Formation, Ziliujing Formation, Xujiahe Formation. The lithology is mainly medium-fine-grained lithic feldspar sandstone, fine-grained lithic quartz sandstone, fine-grained lithic sandstone, medium-grained feldspar quartz sandstone, medium-grained carbonate-containing lithic quartz sandstone, and a small amount of silt Sandy mudstone and mudstone. Marine carbonate formation samples are the cores of P101, P102, and P114 wells, and the layers are the second member of Jia and the third member of Fei, and the lithology is mainly microcrystalline limestone, sandy limestone, and micrite Dolomite, oolitic sandstone limestone, crystalline limestone, etc. The laboratory mainly tests rock elastic modulus, Poisson's ratio, tensile strength, compressive strength, cohesion and internal friction angle.

\section{Results and discussion}

\section{Distribution law of in-situ stress}

\section{The relationship between stress field and regional structure}

Tectonic movement is an important influencing factor of in-situ stress, and has the greatest impact on the horizontal in-situ stress. During continuous movement of earth, the deformation of lithosphere and plate collisions will occur. This phenomenon has led to the imbalance of regional in-situ stress between the plates, and also caused differential deposits. At present, the largest sedimentary basins in the world have experienced the effect of multi-period tectonic stress. Plate tectonic movement changes the tectonic stress field within the plate. The fault block in the oil field is located inside the plate, and its stress field is controlled by the plate tectonic movement ${ }^{[13-15]}$. Because local geological structure has undergone multiple tectonic movements, the internal structure of plate is complicated. The local tectonic stress field is not consistent with the overall regional tectonic stress field. The local tectonic movement has strong directionality, which makes direction of the stress field in this range converge and increases the difference between two horizontal stresses. At the same time, lithology and geological structure cause strong internal rock heterogeneity, which also makes local stress field and the whole region stress field different. Strong tectonic movement and stratigraphic heterogeneity seriously affect the regional stress field. The changes in stress in the rock formations developed by geological structures have also become complicated, as shown in Figure 3. The stronger the regional tectonic movement, the stronger the regularity of distribution of plane stress field and the more stable the direction. The stronger the effect of local geological structure or the heterogeneity of the rock formation, the greater the difference between the local stress field and the regional stress field. The direction change is also greater. 


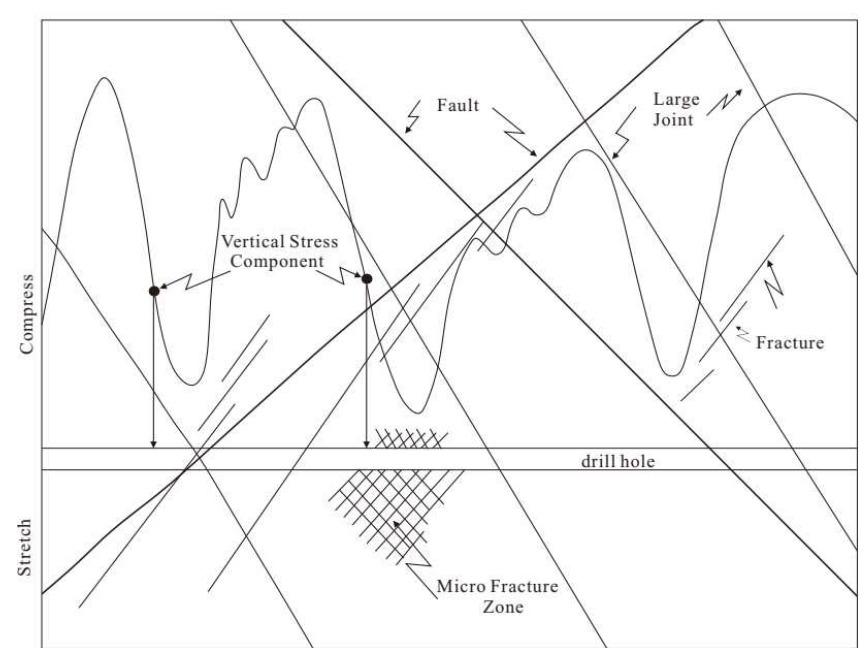

Figure3: Idealized vertical section of rock mass and possible variations of the vertical stress component

The main structural types are faults and folds. In-situ stress near the fault is relatively concentrated and this area belongs to a high-stress area. Cracks and slippage occur under the action of in-situ stress, which leads to redistribution of in-situ stress. Based on two assumptions: (1)The direction of a certain principal stress is vertical. (2)The rock is intact before tectonic movement, and the rock fracture obeys the Mor-coulomb criterion. When there is no violent tectonic activity, the following corresponding relationship between fault type and in-situ stress can be obtained:

When it is a normal fault: the vertical stress is the maximum principal stress $\sigma_{1}$, and the direction of the fault is consistent with the direction of the intermediate principal stress $\sigma_{2}$, as shown in Figure $4(1)$.

When it is a reverse fault: the vertical stress is the minimum principal stress $\sigma_{3}$, and the direction of the fault is consistent with the direction of the intermediate principal stress $\sigma_{2}$, as shown in Figure 4 (2).

When it is a strike-slip fault: the vertical stress is the medium principal stress $\sigma_{2}$, and the angle of intersection between the direction of the fault and the maximum horizontal principal stress $\sigma_{2}$ is less than $45^{\circ}$, as shown in Figure 4 (3).

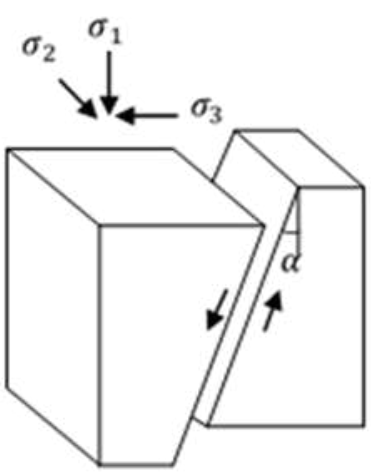

(1) Normal fault

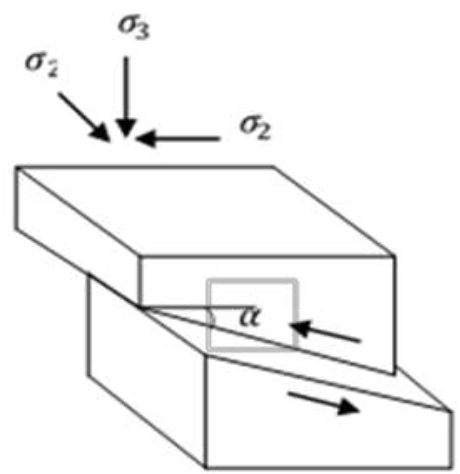

(2) Reverse fault

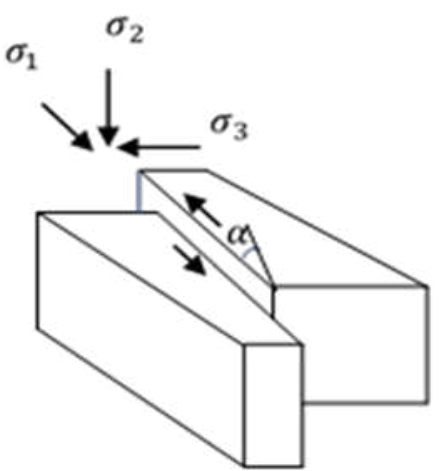

(3) Strike-slip fault

Figure4: Relationship between fault type and in-situ stress

The maximum horizontal in-situ stress at the axis of anticline is generally low, and gradually increases near the wing. The maximum horizontal principal stress at the anticline axis changes rapidly, while at the wing part the change is gentler. The axis of the syncline is a zone of high stress concentration. The steep and dipping zones of the structure are also zoning with high stress 
development. The stress is relatively concentrated, and the main stress direction changes with the change of the structural contours ${ }^{[16-19]}$.

\section{The relationship between in-situ stress and topography}

Topographical conditions are one of the important factors affecting the in-situ stress field of rock mass. In the shallow layer of the ground, the influence of topography on the in-situ stress field is relatively strong. As the depth increases, this influence gradually weakens. This phenomenon is more prominent in northeastern Sichuan. The ground stress is measured by hydraulic fracturing on the surface stratum with a depth of more than 60 meters in northeastern Sichuan. From the measured data, it can be seen that when depth is less than $30 \mathrm{~m}$, data value is too small. Disturbance; when the sounding depth is greater than $30 \mathrm{~m}$, the maximum principal stress direction of all measuring points is the NE direction (Table 1). Obviously, the former is affected by geological factors such as valley slope topography and surface erosion, river erosion ${ }^{[20-22]}$. The water fracturing method was used to measure the eastern Sichuan depression zone. The same result (Figure 5) was obtained. The maximum horizontal ground stress near the surface is consistent with the topographic direction. When the sounding depth is less than 30 meters, the maximum principal stress direction is related to the fracture. The direction is consistent, and the tectonic activity affects the direction of the principal stress.

Table1: Stress measurement results of shallow borehole in Northeast Sichuan

\begin{tabular}{ccccc}
\hline Number & Depth(m) & $\sigma_{\mathrm{H}}(\mathrm{MPa})$ & $\sigma_{\mathrm{h}}(\mathrm{MPa})$ & Direction \\
\hline \multirow{4}{*}{ NO.10 } & 17.6 & 18.0 & 5.0 & $\mathrm{~N} 78^{\circ} \mathrm{W}$ \\
& 24.5 & 50.0 & 12.0 & $\mathrm{~N} 87^{\circ} \mathrm{E}$ \\
& 30.0 & 18.0 & 30.0 & $\mathrm{~N} 80^{\circ} \mathrm{W}$ \\
& 37.5 & 65.0 & 29.1 & $\mathrm{~N} 34^{\circ} \mathrm{E}$ \\
& 40.5 & 65.9 & 25.9 & \\
& 45.0 & 49.4 & 20.2 & \\
& 55.3 & 60.0 & 31.5 & $\mathrm{~N} 50^{\circ} \mathrm{E}$ \\
\hline \multirow{3}{*}{ NO.11 } & 21.9 & 15.0 & -10 & $\mathrm{~N} 28^{\circ} \mathrm{E}$ \\
& 26.8 & 11.0 & -20 & $\mathrm{~N} 6^{\circ} \mathrm{E}$ \\
& 38.0 & 14.5 & 12.6 & $\mathrm{~N} 32^{\circ} \mathrm{E}$ \\
& 45.0 & 39.4 & 24.8 & $\mathrm{~N} 12^{\circ} \mathrm{E}$ \\
& 53.5 & 50.7 & 22.6 & $\mathrm{~N} 32^{\circ} \mathrm{E}$ \\
\hline
\end{tabular}

In the eastern Sichuan region, the uplift terrain increases the maximum horizontal principal stress value, and difference between the maximum and minimum horizontal principal stresses gradually increases, which aggravates the dynamic environment of dynamic disasters. In the valley area, rock mass at the bottom of the valley is a concentrated area of in-situ stress. The stress is consistent with the horizontal direction and perpendicular to the valley direction (Figure 5). As the angle between valley direction and regional principal stress direction gradually increases, the range of the stress concentration area gradually expands, and the principal stress gradually increases. In the valley slope rock mass, the magnitude and direction of principal stress depend on the direction of regional stress field. When the angle between principal stress and regional stress field gradually increases, in-situ stress concentration in the valley slope rock mass increases, and maximum principal stress direction changes from the initial. The direction of maximum principal stress is close to the area and tends to be perpendicular to the valley gradually. 


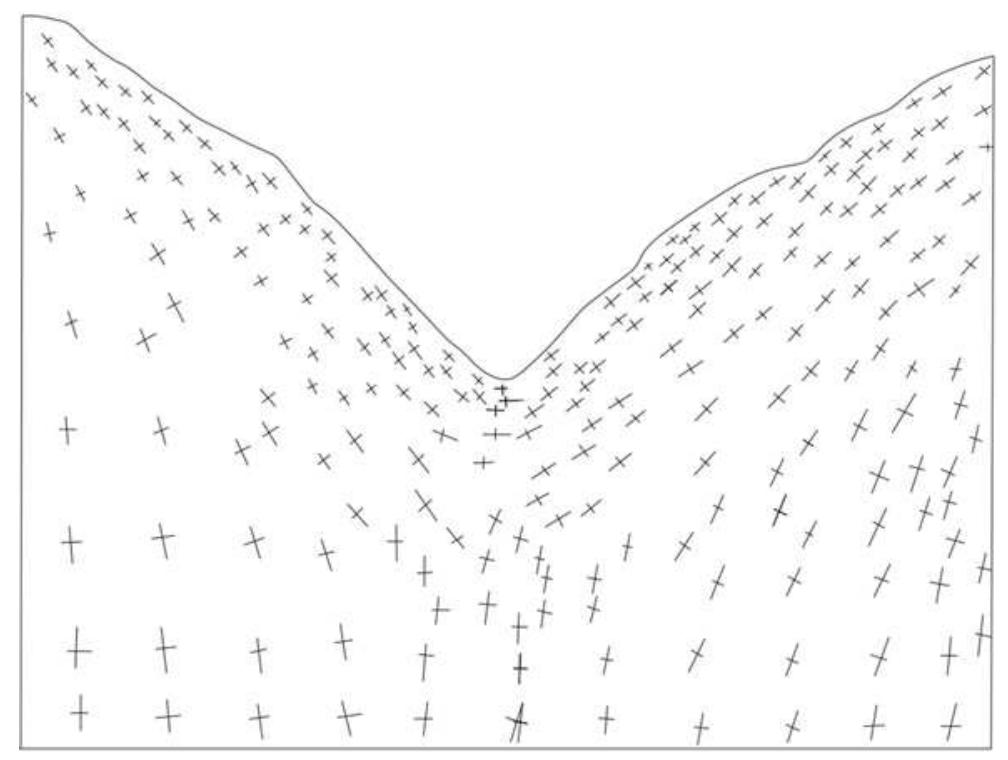

Figure5: Principal stress vector diagram at valley

\section{Variation law of in-situ stress value with buried depth}

\section{Variation law of vertical stress with buried depth}

In this paper, statistical analysis of vertical stress $\sigma_{V}$ in northeastern Sichuan and northwest Sichuan are based on acoustic emission experimental data. Because in-situ stress of shallow strata is greatly affected by topography and geomorphology, this statistical analysis does not consider data with buried depth of less than 100 meters. The vertical in-situ stress in the Sichuan Basin varies with depth, as shown in Figures 6(a) and 6(b). Figures 6(a) and 6(b) show that although vertical stress in the Sichuan Basin has a certain degree of dispersion, overall vertical stress increases with the increase of buried depth, and changes in a linear relationship. This is similar to statistical results of Hoek\&Beown and Zhu Huanchun. After linear regression, the regression formulas of vertical ground stress in the northeast and west of Sichuan Basin with burial depth can be obtained as follows:

$$
\left.\begin{array}{cc}
\text { Northeast of Sichuan: } & \sigma_{V}=0.0261 H, R^{2}=0.989 \\
\text { West of Sichuan: } & \sigma_{V}=0.0247 H, R^{2}=0.916
\end{array}\right\} \text { (1) }
$$

Where: $\mathrm{H}$ is the buried depth, $\mathrm{m} . \sigma_{V}$ is the vertical stress, MPa.

From the perspective of vertical stress variation with depth, the gradient of change in northeastern Sichuan is greater than that in western Sichuan. The overall bulk density of the overlying rock is about $25 \sim 30 \mathrm{kN} / \mathrm{m}^{3}$. Therefore, vertical stress in the Sichuan Basin changes with depth of the buried depth, which is roughly similar to the bulk density of the rock. It further shows that the main component of the vertical stress $\sigma_{V}$ is the rock's own weight. 


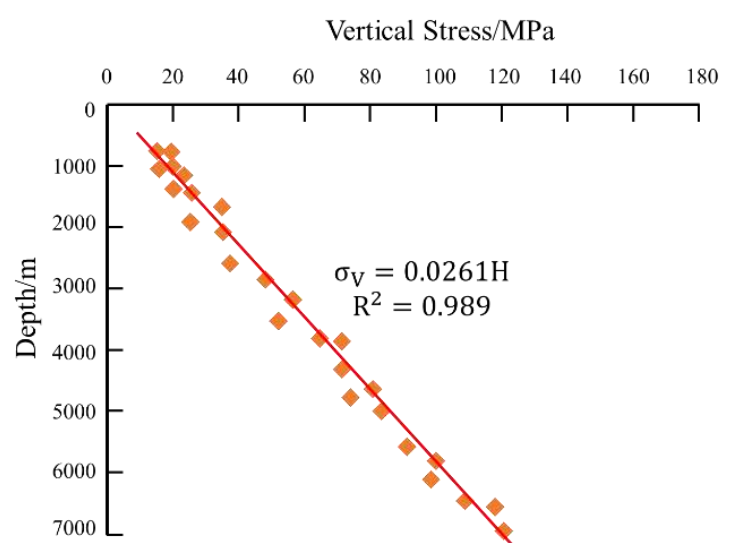

(a) Variation of vertical stress with buried depth in northeastern Sichuan

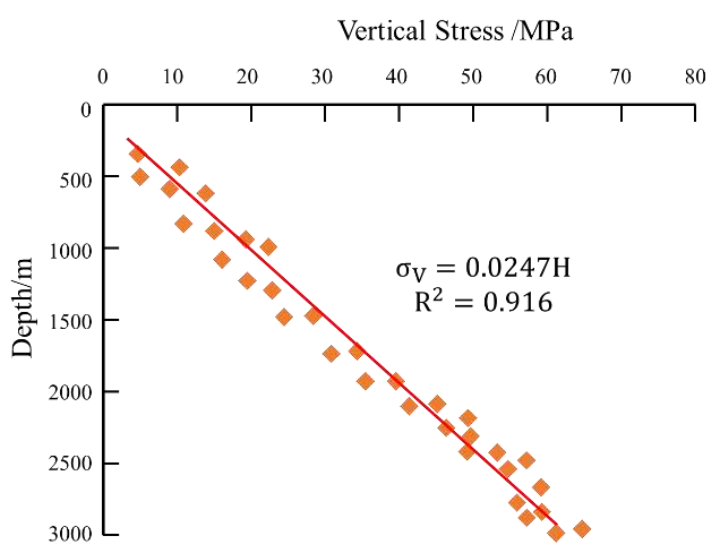

(b) Variation of vertical stress with buried depth in western Sichuan

Figure6: Variation of vertical stress with depth in the Sichuan Basin

\section{Variation of horizontal principal stress with buried depth}

The distribution of maximum and minimum horizontal principal stresses in the Sichuan Basin with buried depth is shown in the figure (Figure7,8), which is linearly related to buried depth as a whole. Performing linear regression on the in-situ stress data, and get regression equation of maximum and minimum horizontal principal stress with buried depth (Table 2).

Table 2: Regression coefficients of horizontal principal stress in the Sichuan Basin

\begin{tabular}{ccccc}
\hline Area & Stress Type & Coefficient & Constant & $R^{2}$ \\
\hline $\begin{array}{c}\text { Northeastern } \\
\text { Sichuan }\end{array}$ & $\sigma_{H}$ & 0.0234 & 10.6 & 0.904 \\
& $\sigma_{h}$ & 0.0216 & 3.16 & 0.931 \\
Western Sichuan & $\sigma_{H}$ & 0.0207 & 3.38 & 0.926 \\
& $\sigma_{h}$ & 0.0192 & 1.16 & 0.946 \\
\hline
\end{tabular}

It can be seen from Figures 7 and 8 , that although the maximum and minimum horizontal principal stresses of the entire Sichuan Basin have a certain degree of dispersion, they tend to increase as the depth increases. The entire Sichuan Basin shows $\sigma_{H}$ is greater than $\sigma_{h}$,indicating that the fault activity in this area is mainly strike-slip type. It can be seen from Table 2 that the regression equation consists of a coefficient term and a constant term. The coefficient term represents the degree of horizontal principal stress change, and the constant term represents the in-situ stress in the shallow formation. Compared with the coefficient term of the vertical stress, the coefficient term of the maximum and minimum horizontal stress is smaller than the value corresponding to the vertical stress, indicating that the degree of the vertical stress varies with buried depth is greater than the horizontal principal stress. The value of the constant term in northeastern Sichuan is greater than that in western Sichuan, indicating that the value of shallow ground stress in northeastern Sichuan 
is greater than that in western Sichuan.

Table3: Regression coefficients of horizontal principal stresses in other basins in China (Ge Hongkui, 1998)

\begin{tabular}{cccc}
\hline Area & Stress Type & Coefficient & Constant \\
\hline \multirow{2}{*}{ North China Plain } & $\sigma_{H}$ & 0.03 & -10.5 \\
& $\sigma_{h}$ & 0.021 & -5.87 \\
& $\sigma_{H}$ & 0.03 & -22.58 \\
Qaidam Basin & $\sigma_{h}$ & 0.022 & -11.65 \\
& $\sigma_{H}$ & 0.0266 & -2.34 \\
Songliao Basin & $\sigma_{h}$ & 0.0182 & -0.777 \\
& $\sigma_{H}$ & 0.022 & 0.7 \\
Bohai Bay Basin & $\sigma_{h}$ & 0.018 & 0.5 \\
\hline
\end{tabular}

Compared with the horizontal principal stress of other basins in China, the regression coefficient of the maximum horizontal principal stress in the Sichuan Basin and the Bohai Bay Basin are smaller, but smaller than that of the North China Plain, Qaidam Basin, and Song Liao Basin (Table 3). It shows that the degree of variation of the maximum horizontal principal stress with depth in the Sichuan Basin is smaller than that of other basins. The minimum horizontal principal stress of the Sichuan Basin is not much different from other basins, indicating that the minimum horizontal principal stresses of these blocks have similar changes with depth. However, the constant term in the Sichuan Basin is positive, and the constant terms in the Song Liao Basin, the North China Plain, and the Qaidam Basin are all negative. Although the constant term in the Bohai Bay Basin is positive, it is also smaller than the constant term in the Sichuan Basin, indicating that a certain amount of horizontal principal stress still exists in the shallow part of the crust in the Sichuan Basin, while the corresponding shallow parts of the Song Liao Basin, North China Plain, and Qaidam Basin are in a state of under pressure equilibrium, and the shallow parts of the Bohai Bay Basin are in a state of stress equilibrium. 

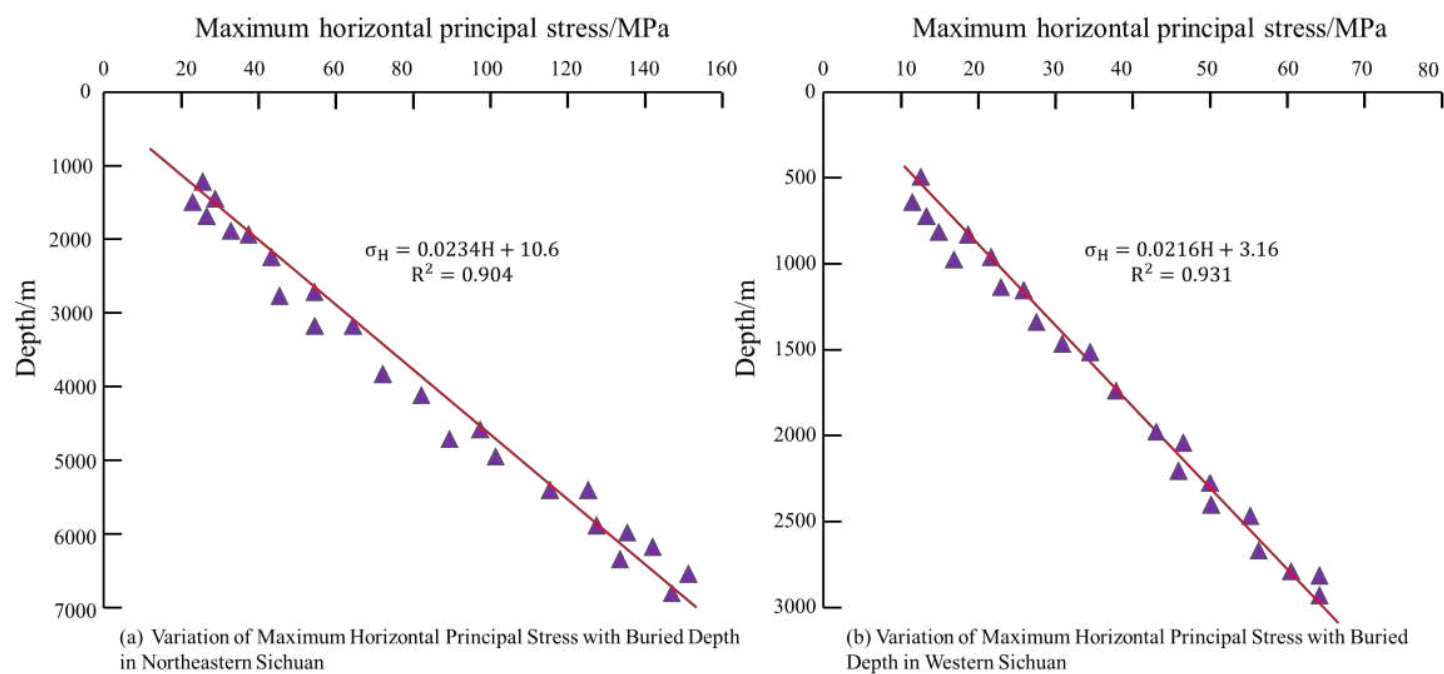

Figure7: Variation of maximum horizontal principal stress with depth in the east and west of the Sichuan Basin

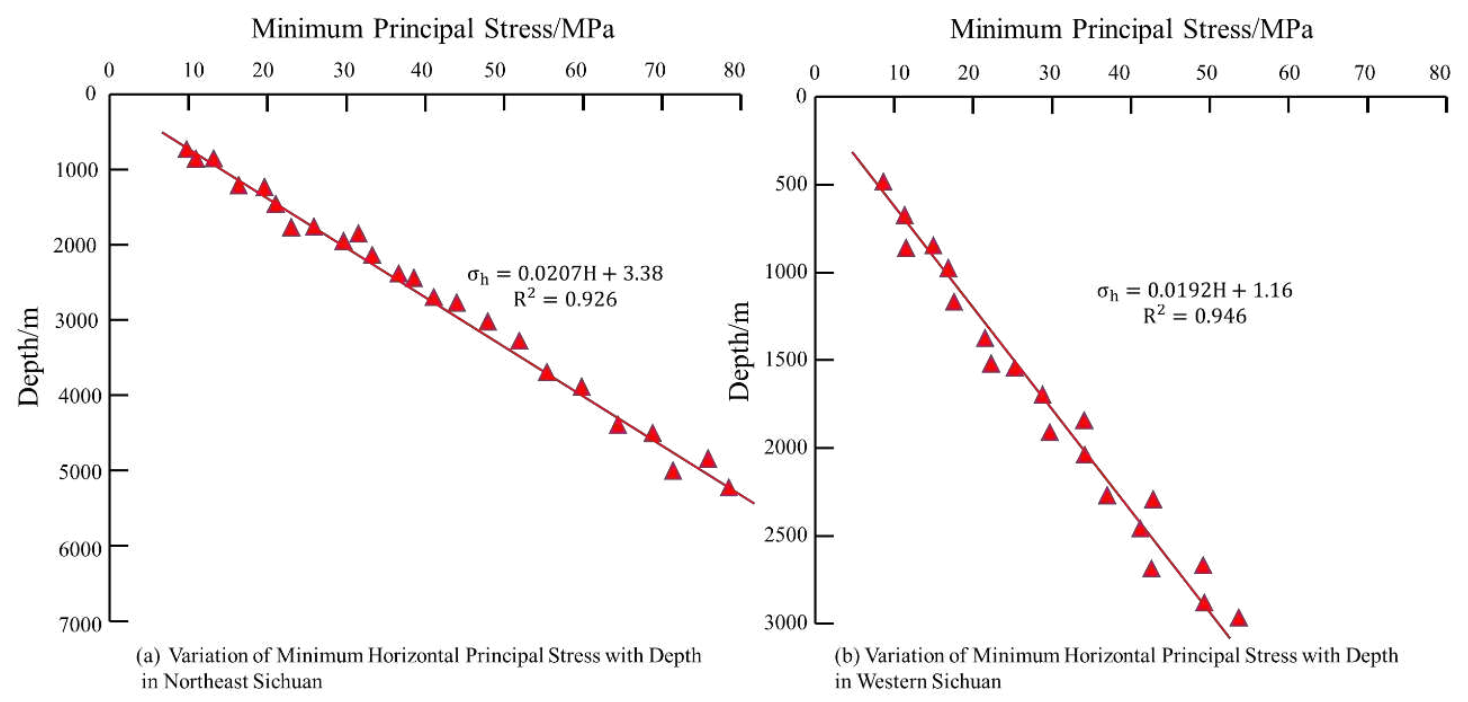

Figure8: Variation of minimum horizontal principal stress with buried depth in the east and west of the Sichuan Basin

\section{Variation of lateral pressure coefficient with buried depth}

In the study of in-situ stress, $\mathrm{k}$ is often used to express the lateral pressure coefficient, which is often used to describe the stress state of a certain point ${ }^{[23-25]}$. A large number of studies have shown that, under normal circumstances, vertical stress is very close to the weight of the rock mass, especially for deep rock masses, indicating that the horizontal stress and weight of the rock mass can be used to express the stress state of a certain point. Brown-Hoek used $\frac{\sigma_{\mathrm{H}}+\sigma_{\mathrm{h}}}{2 \sigma_{\mathrm{V}}}$ to study the distribution of in-situ stress in the world. This formula is the average horizontal principal stress, that is, average value of the maximum and minimum horizontal principal stress, and the ratio of vertical principal stress. This paper refers to a method similar to this analysis method, regression analysis of the law of lateral pressure coefficient changing with depth in the Sichuan Basin.

Assuming that the ratio of average horizontal stress to vertical stress is $\mathrm{k}, \mathrm{k}$ is the lateral pressure coefficient: 


$$
\mathrm{k}=\frac{\sigma_{\mathrm{H}}+\sigma_{\mathrm{h}}}{2 \sigma_{\mathrm{V}}}
$$

Assume again: $\mathrm{k}=\mathrm{a} / \mathrm{H}+\mathrm{b}, 1 / \mathrm{H}=\mathrm{x}$, and $\mathrm{a}$ and $\mathrm{b}$ are regression coefficients respectively. It can be considered that $\mathrm{k}$ and the reciprocal of depth are linear.

Before regression, linearizing the lateral pressure coefficient and $1 / \mathrm{H}$ to obtain regression formula of the lateral pressure coefficient and depth in northeastern Sichuan and western Sichuan, seeing equation (3), and the inner and outer envelope curves are shown in Figure 9.

$$
\begin{aligned}
& k=\frac{181.72}{H}+0.85 \\
& k=\frac{197.86}{H}+1.26
\end{aligned}
$$

In the range of shallow buried depths of less than 800 meters, the lateral pressure coefficient in western Sichuan varies between 1 and 6, while that in northeastern Sichuan varies between 1 and 2 . However, if the burial depth exceeds 1,000 meters, the rate of decrease of the lateral pressure coefficient in the northeastern part of Sichuan is lower than that in the western part of Sichuan.

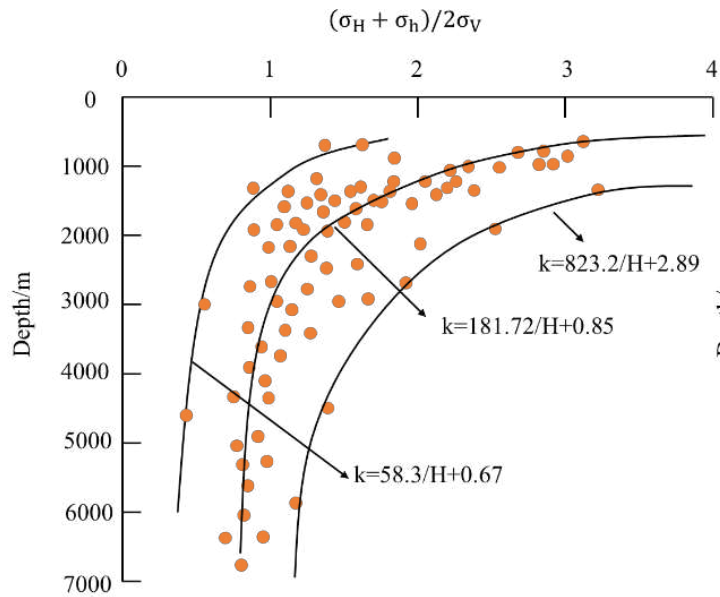

(a) The distribution of the ratio of horizontal average stress to vertical stress with buried depth in northeastern Sichuan

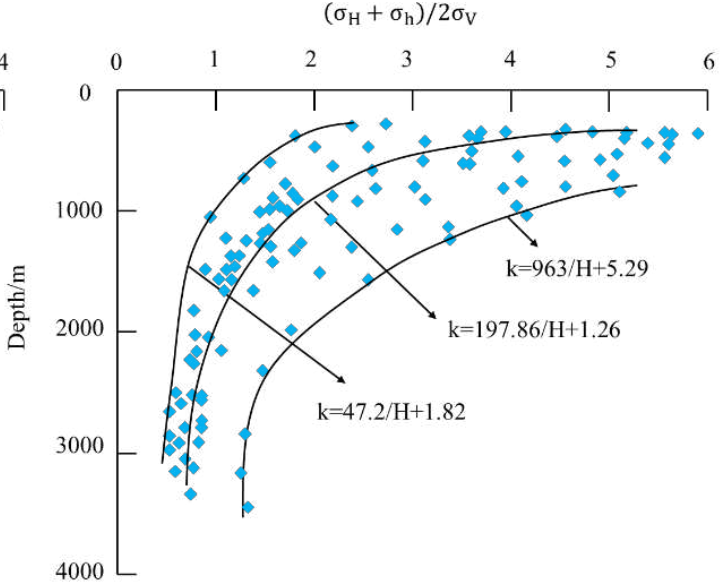

(b) The distribution of the ratio of horizontal average stress to vertical stress with buried depth in West Sichuan

Figure 9: The ratio of the horizontal average in-situ stress to the vertical stress in the eastern and western parts of the Sichuan Basin

\section{The distribution law of horizontal shear stress with buried depth}

The distribution of horizontal shear stress in northeastern and western Sichuan with depth (Figure 10) shows that the horizontal shear stress in the northeastern and western Sichuan Basin has a linear relationship with depth, but the degree of change between the two is different. From the perspective of dispersion, the northeastern part of Sichuan is more dispersed than the western part of Sichuan. 


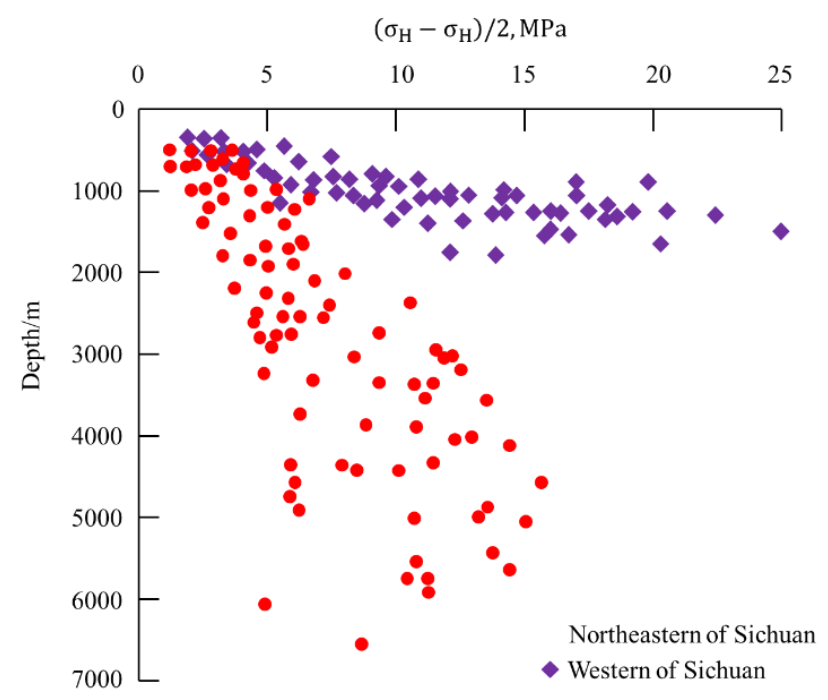

Figure10: Distribution of horizontal shear stress with depth in northeastern Sichuan and western Sichuan

\section{Variation of principal stress with elastic modulus and Poisson's ratio}

From the view of energy accumulation, in-situ stress is the result of energy accumulation and release. The upper limit of rock stress must be limited by the strength of rock, and the strength of rock has a positive correlation with the elastic modulus ${ }^{[26,27]}$. Rocks with larger elastic modulus and better integrity are conducive to accumulation of high stress ${ }^{[28]}$. Studies have shown that the mechanical properties of rocks have a significant impact on the in-situ stress, and the difference in rock mechanical properties will affect the stress state that it occurs. The elastic modulus of rock generally increases with buried depth. The elastic modulus of rock directly affects the value of stress that occurs. Generally speaking, the higher the elastic modulus of the rock, the better it is to keep it higher. stress. Calculate the measured data of the maximum and minimum horizontal principal stress and elastic modulus of 20 groups of carbonate rocks, 16 groups of sandstone, and 8 groups of mudstone under the same stress environment of 4 wells in an oilfield in Sichuan, and establish the scatter point distribution figure of in-situ stress and elastic modulus (Figure 11). The analysis shows that under the same stress environment, the elastic modulus of carbonate rock and sandstone is positively correlated with the maximum horizontal principal stress and negatively correlated with the minimum principal stress. However, due to unstable strength and uneven mineral composition of mudstone, as a result, the correlation between the elastic modulus and the applied stress is not very obvious. Because the strength of carbonate rock is greater than that of sandstone, the change in elastic modulus has a greater impact on the maximum horizontal principal stress of carbonate rock than sandstone, and the impact on the minimum principal stress of sandstone is greater than that on carbonate rock. In carbonate rock, the effect of elastic modulus on the minimum horizontal principal stress is greater than the maximum horizontal principal stress, while in sandstone it is the opposite. 


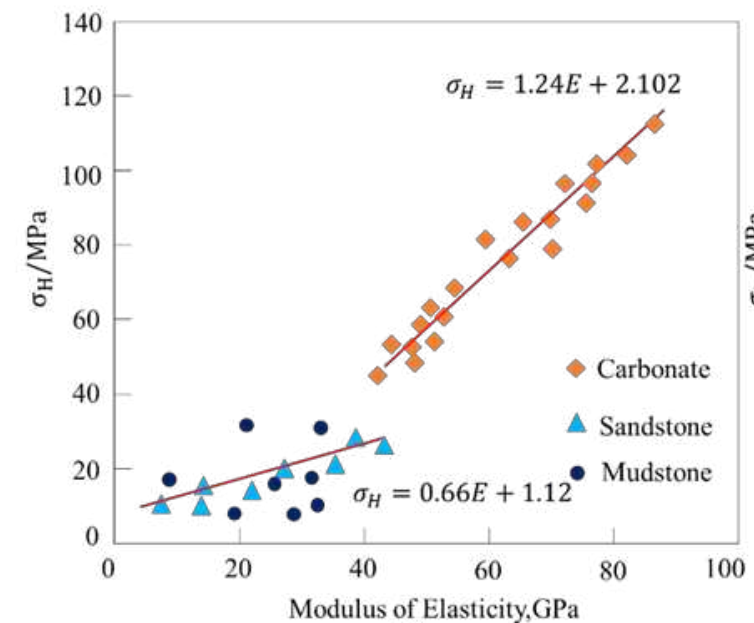

(a)

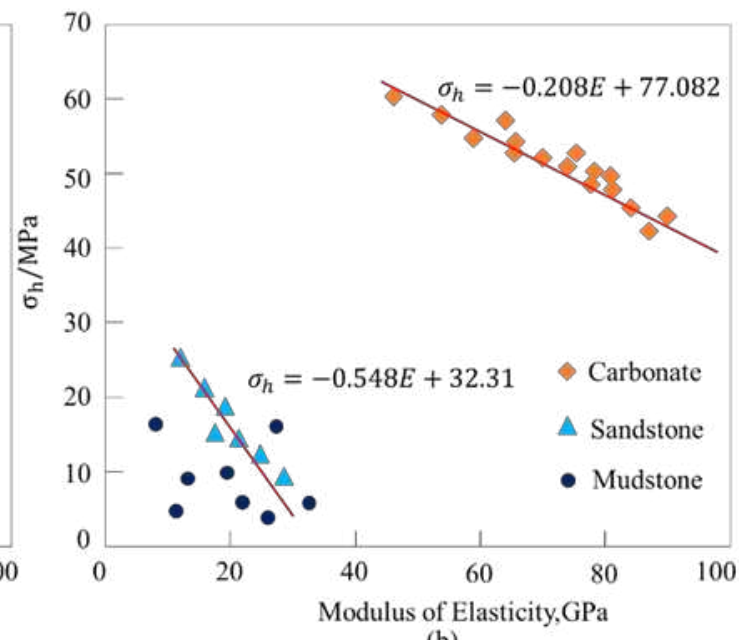

(b)

Figure11: The relationship between elastic modulus and maximum and minimum stress

Counting the measured data of Poisson's ratio and horizontal principal stress of 20 groups of carbonate rocks, 18 groups of sandstones, and 8 groups of mudstone in an oil field in Sichuan, and establishing a scatter plot of Poisson's ratio and horizontal principal stress (Figure 12). Analysis shows that Poisson's ratio has little effect on the horizontal principal stress of carbonate rocks, but has a greater effect on the horizontal principal stresses of sandstone and mudstone. Poisson's ratio is positively correlated with the horizontal principal stress of these two types of rocks. The change of Poisson's ratio has a greater influence on the horizontal stress of mudstone than sandstone. The main reason for this phenomenon is that the mudstone is relatively soft, the rock strength is not high, and it is easy to deform.

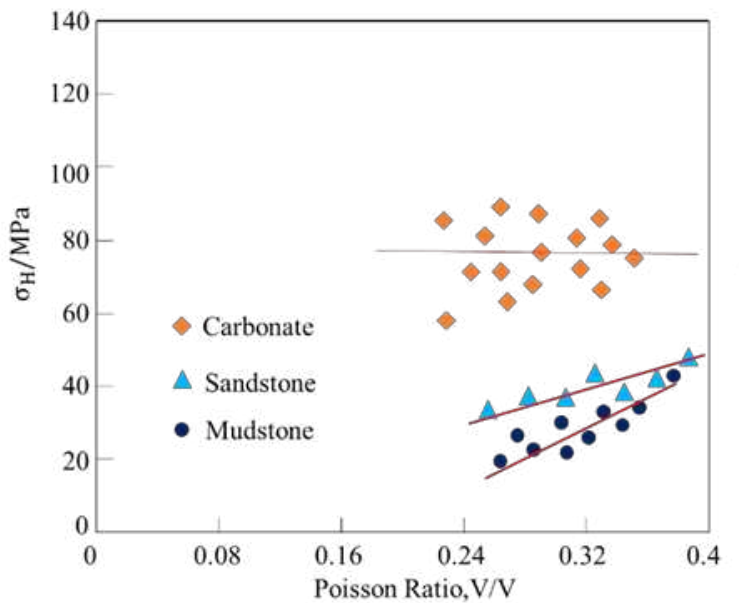

(a)

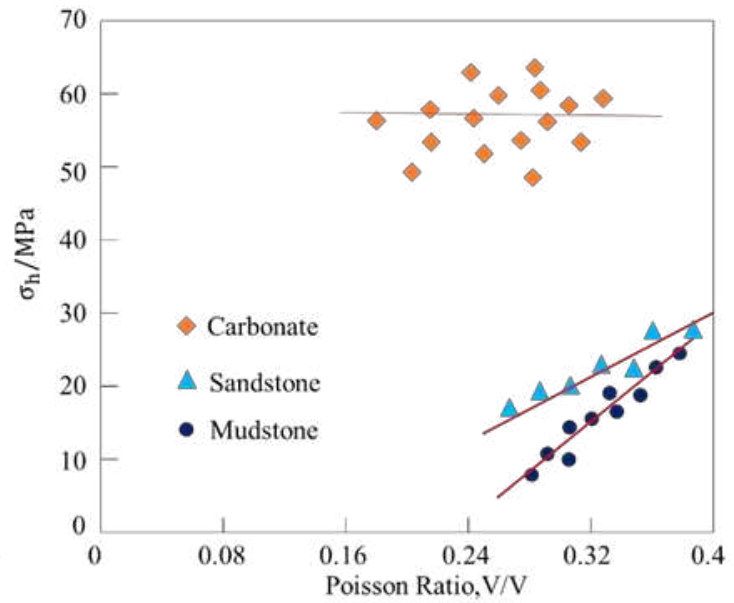

(b)

Figure12: The relationship between Poisson's ratio and horizontal principal stress

\section{Conclusions}

In this paper, combined with experimental data, a statistical analysis of the distribution of in-situ stress in the east and west of the Sichuan Basin, the following conclusions are obtained:

(1) In-situ stress is affected by regional structure and topographical factors. Among them, the horizontal principal stress is the strongest affected by the structure. The horizontal stress is generally low at the axis of the anticline, and gradually increases near the wing. The uplift terrain increases 
the maximum horizontal principal stress value, and the difference between the maximum and minimum horizontal principal stresses gradually increases, which aggravates the dynamic environment of dynamic disasters. In valley areas, the rock mass at the bottom of the valley is an area of in-situ stress concentration, and the maximum horizontal principal stress is consistent with the horizontal direction perpendicular to the valley.

(2) The vertical stress and horizontal principal stress in the east and west of the Sichuan Basin generally increase with the increase of buried depth, and change in a linear relationship. The degree of variation of vertical and horizontal principal stress with buried depth in eastern Sichuan is greater than that in western Sichuan. The vertical principal stress in eastern and western Sichuan is generally close to the weight of the rock.

(3) The elastic modulus of rock directly affects the stress value of the rock. Generally, the higher the elastic modulus of the rock, the better it is to maintain a higher stress. The elastic modulus of rocks of different genesis is obviously different, and the relationship between stress value of rock and the elastic modulus is quite different. Because the strength of carbonate rock is greater than that of sandstone, the influence of the change of elastic modulus on the maximum horizontal principal stress of carbonate rock is greater than that of sandstone, while the influence on the minimum principal stress of sandstone is greater than that of carbonate rock. The effect of elastic modulus on the minimum horizontal principal stress is greater than that on the maximum horizontal principal stress in carbonate rock, but it is opposite in sandstone.

Due to wide area and complex geological conditions of the whole Sichuan Basin, it is difficult to obtain the actual in-situ stress data. The law obtained based on the limited data in this paper is not necessarily comprehensive, but it is still representative to some extent, which can be used as a reference for the exploration and development of oil and gas fields in Sichuan Basin and other geoscience studies.

Availability of data and materials Most Data in this paper were acquired by experimental test in the State Key Laboratory of "Oil and Gas Reservoir Geology and Development Engineering" of Chengdu University of Technology using "MTS Rock Physics Parameter Test System", and the "State Key Laboratory of Geological Hazard Prevention and Environmental Protection" of Chengdu University of Technology based on American products, the American MTS815 programmable servo rigidity testing machine. Some were acquired by through drilling testing.

Competing interests The authors declare that they have no competing interests.

Funding Funding was supported by the National Science and Technology Major Project [grant NO.2019ZX06008-003]

Authors' contributions Xinxin Fang proposed the idea, analyzed the data, and completed this paper. Other authors discussed the structure of this paper.

Acknowledgements We would like to acknowledge the use of data and instructions of Prof.Feng and my cooperating team. We thank data collection of my colleague and discussion about paper structure.

Authors' information ${ }^{1}$ China Coal Research Institute, Beijing. ${ }^{2}$ China Coal Technology \& Engineering Group Xian Institute, Xian 710077, Shanxi, China.

\section{References}

[1]Yan Changhua(2002)Chen Qing, Zhou Wen.Characteristics of the current in-situ stress field of the Penglai Zhen Formation in Luodai Gas Field[J].Natural Gas Industry.22 (2): 106 107. 
[2] Cai Meifeng (1997) Research on the relationship between in-situ stress state and surrounding rock properties.

[3] Zhan Fenglin (2006) The influence of ground temperature gradient on the calculation of ground stress in underground mines. Mining Research and Development.6 (2) :24 36.

[4] Jing Feng (2008) Statistical analysis of the distribution law of in-situ stress of rocks with different geological origins. Rock and Soil Mechanics.29(7):1877 1889.

[5] Pei Qitao (2016) Theoretical and experimental research on the relationship between in-situ stress and rock mass modulus. Glacier Permafrost.38(4):879 882.

[6] Kang Hongpu, Lin Jian, Zhang Xiao (2010) Study on measurement and distribution of underground stress in Lu'an mining area. Rock and Soil Mechanics.31(3):827 839.

[7] Brady, B.H.G. Rock Mechanics for underground mining.1985. George Allen \& Unwin, London.

[8] Hudson J. A. and Harrison J. P. (1997) Engineering rock mechanics: an introduction to the

Principals, Elsevier, Oxford

[9] Zhao Dean, Chen Zhimin, Cai Xiaolin (2007) Statistical analysis on the distribution law of insitu stress field in China[J]. Chinese Journal of Rock Mechanics and Engineering.26(6): 1265 1278. [10] Jing Feng, Sheng Qian, Zhang Yonghui (2007) Study on the distribution of measured in-situ stress in the shallow crust of the Chinese mainland[J]. Chinese Journal of Rock and Soil Mechanics and Engineering.26(10): 2056 2068.

[11] Zhu Huanchun, Tao Zhenyu (1994) Preliminary analysis of topography and in-situ stress distribution[J]. Water Resources and Hydropower Technology.1(12): 27 28.

[12] Kang Hongpu, Yi Bingding, Gao Fuqiang (2019) In-situ stress database and in-situ stress distribution law of coal mines in China[J]. Journal of China Coal Society.44(1): 24 36.

[13] Yang Zhibin (2011) Research on Engineering Geological Characteristics of River Dam Structure and Drilling Countermeasures in Northeast Sichuan.

[14] Kang Hongpu, Wu Zhigang, Gao Fuqiang (2012) The influence of underground coal mine geological structure on the distribution of in-situ stress. Rock and Soil Mechanics and Engineering.31(5): 2674 2688.

[15] C.L. Cipolla, Diabin Liu (2010) Practical Application of In-Situ Stress Profiles.SPE.2 (20): 486 492.

[16] Ge Hongkui, Lin Yingsong (1998) The distribution law of in-situ stress in the oilfield.Fault block oil and gas field.5(5):1 10.

[17] Che Yongtai (1983) Introduction to Rock Mass Engineering Geology. Geological Press.

[18] Wu Guodai, Sang Shuxun, Yang Zhigang (2009) Research status and prospects of the influence of in-situ stress on coalbed methane exploration and development[J]. China Coal Geology.21(4):31 43.

[19] Wang Shuo, Dai Junsheng, Fu Xiao long (2016) Numerical simulation of current in-situ stress field and analysis of influencing factors in the third member of Shahejie Formation in Block 5 of Bonan Oilfield. Petroleum Geology and Recovery Efficiency.23(3): 26 37.

[20] Bai Shiwei, Li Guangyu (1982) Study on the rock mass stress field in the dam area of Ertan Hydropower Station. Rock and Soil Mechanics and Engineering.20(6): 38 49.

[21] Huang Runqiu, Wang Shitian, Hu Xiewen (1992) Research on major engineering geological problems of the high arch dam foundation of the Xiaowan Hydropower Station on the Lancang River. Southwest Jiao tong University Press.

[22] Zhao Shiguang (1984) The near-surface and deep in-situ stress measurement of the middle 
section of the Tanlu fault. Journal of Seismology.31(4): 48 55.

[23] Jing Feng, Bian Zhihua, Chen Hao (2008) Statistical analysis on the distribution of lateral pressure coefficients of different lithologies. Journal of Yangtze River Scientific Research Institute.25(4): 48 59.

[24] Zhang Dongtao, Tong Xiangmao, Zhao Haitao (2014) Characteristics and laws of longitudinal distribution of in-situ stress in sand and mudstone formations. Chinese Journal of Geomechanics.20(4): 353 367.

[25] Kang Hongpu, Lin Jian, Zhang Xiao (2007) Research and application of in-situ stress measurement methods in deep mines. Chinese Journal of Rock Mechanics and Engineering.26(5): 929 938.

[26] Chen Shida, Tao Shu, Xu Hao (2018) Statistical analysis of macroscopic distribution law of insitu stress field in coalbed methane reservoir. Coal Science and Technology.46(6): 57 69.

[27] Liu Yun fang, Liu Yuankun (1999) Study on three-dimensional in-situ stress measurement method of hydraulic fracturing[J]. Crustal Deformation and Earthquake.19(3): 64 78.

[28] Li Xinping, Wang Bin, Zhou Guilong (2012) Study on the distribution law of in-situ stress in the measured depth of my country's continent. Chinese Journal of Rock Mechanics and Engineering.31(8): 2875 2880. 


\section{Figures}

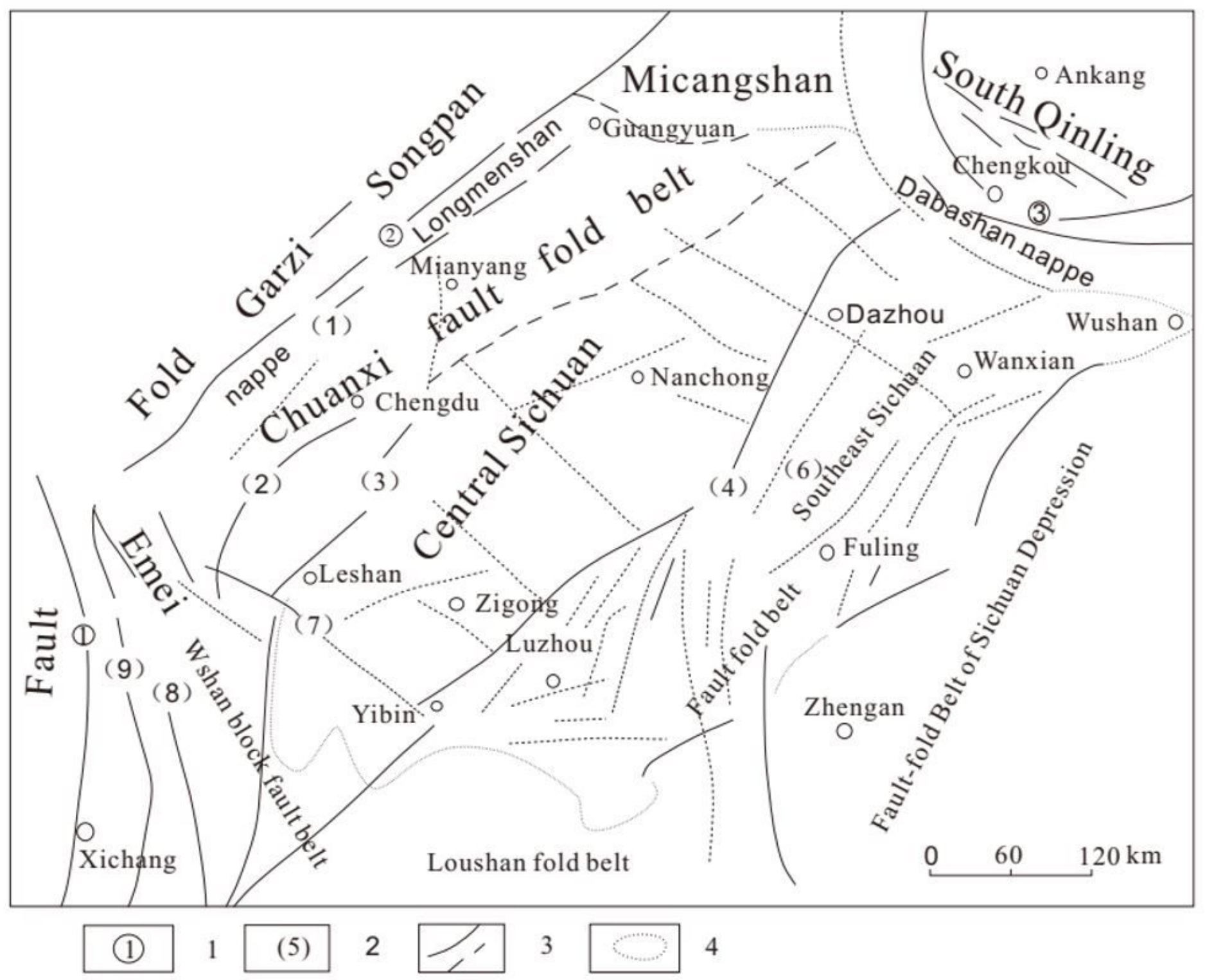

\section{Figure 1}

Regional structural map of Sichuan Basin (Adapted from Yang Zhibin, 2011) 1. Deep and large

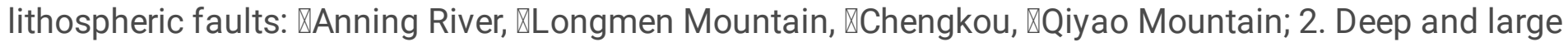
crustal faults: (1) Peng Guan, (2) Xiongpo, (3) Long Quan Mountain, (4) Huaying Mountain, (5) WuxiTiexi, (6) Huangnitang, (7) Emei-Washan, (8) Ganluo-Xiaojiang, (9) Puxiong-Pudu River; 3. Large deep faults in the caprock (including basement faults); 4. Basin scope Note: The designations employed and the presentation of the material on this map do not imply the expression of any opinion whatsoever on the part of Research Square concerning the legal status of any country, territory, city or area or of its authorities, or concerning the delimitation of its frontiers or boundaries. This map has been provided by the authors. 


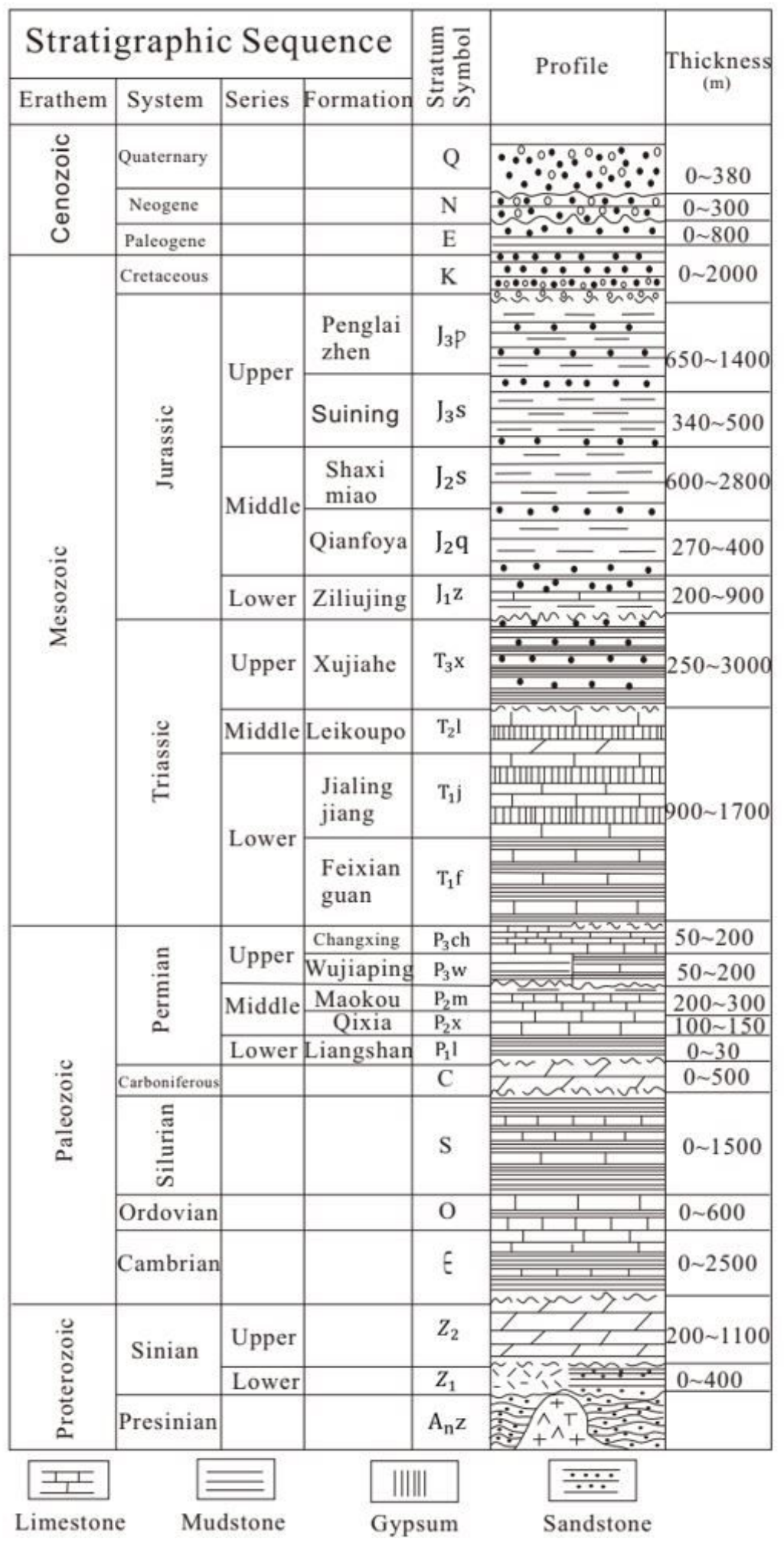

Figure 2

Comprehensive histogram of Sichuan Basin strata (Adapted from Yang Zhibin, 2011) 


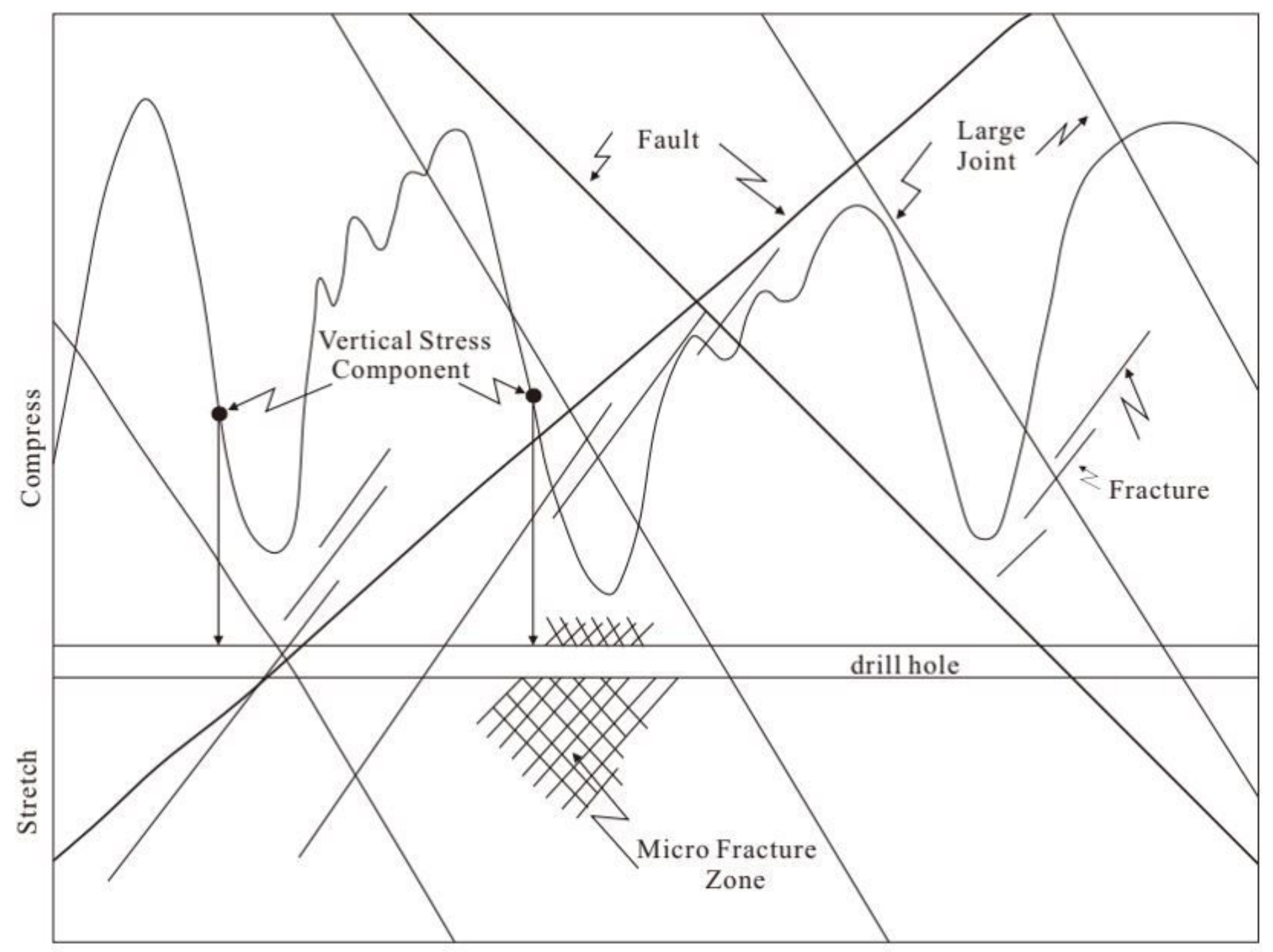

Figure 3

Idealized vertical section of rock mass and possible variations of the vertical stress component

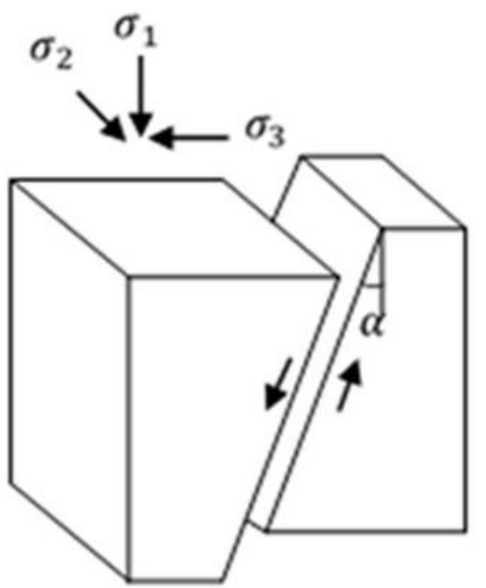

(1) Normal fault

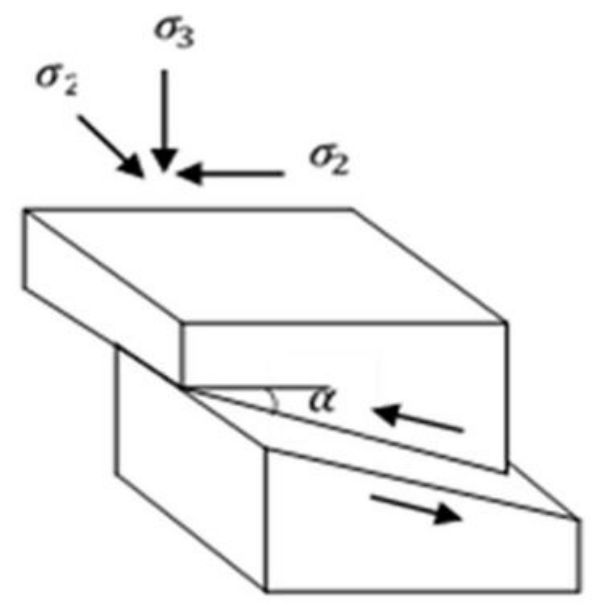

(2) Reverse fault

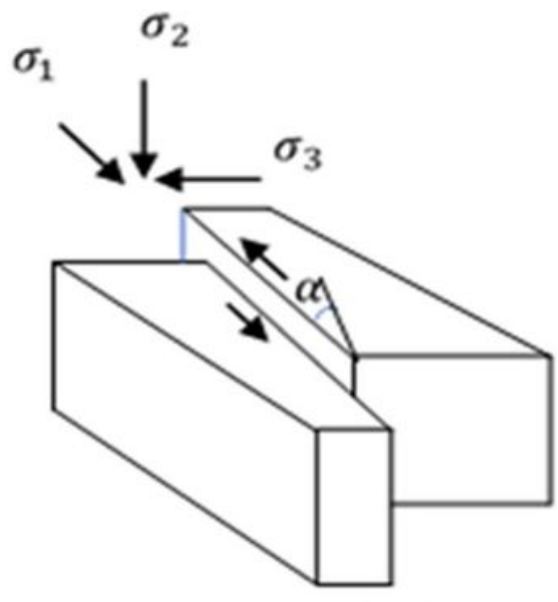

(3) Strike-slip fault

Figure 4 


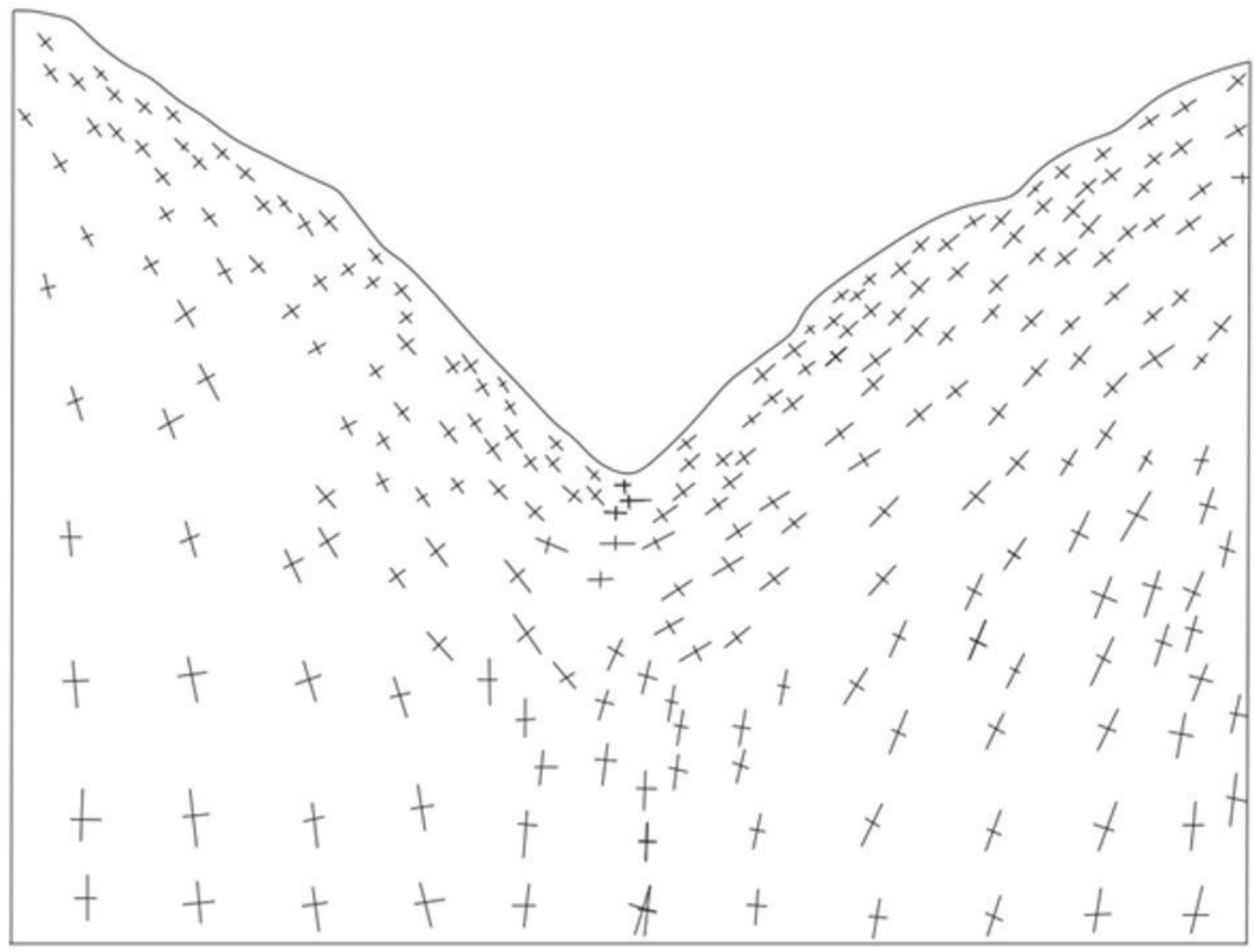

\section{Figure 5}

Principal stress vector diagram at valley

Vertical Stress/MPa

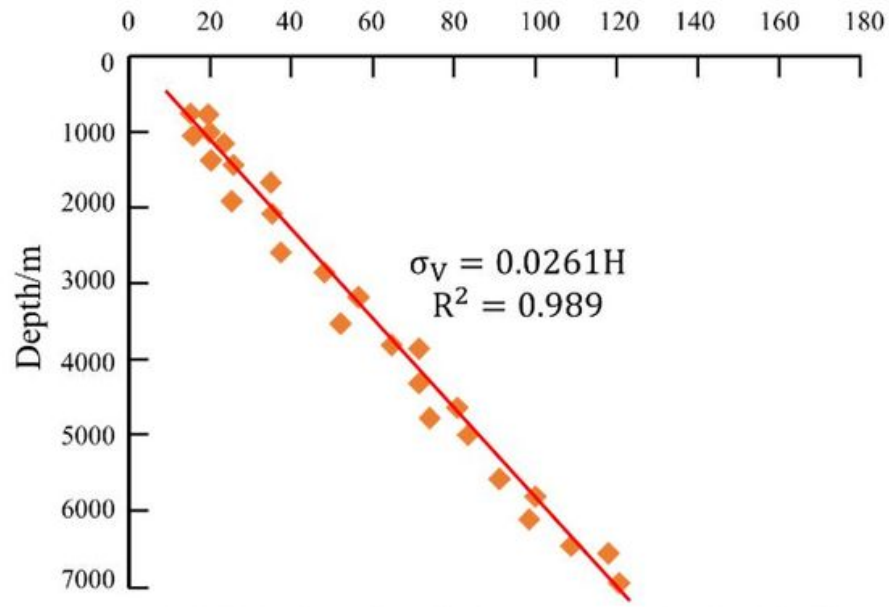

(a) Variation of vertical stress with buried depth in northeastern Sichuan
Vertical Stress /MPa

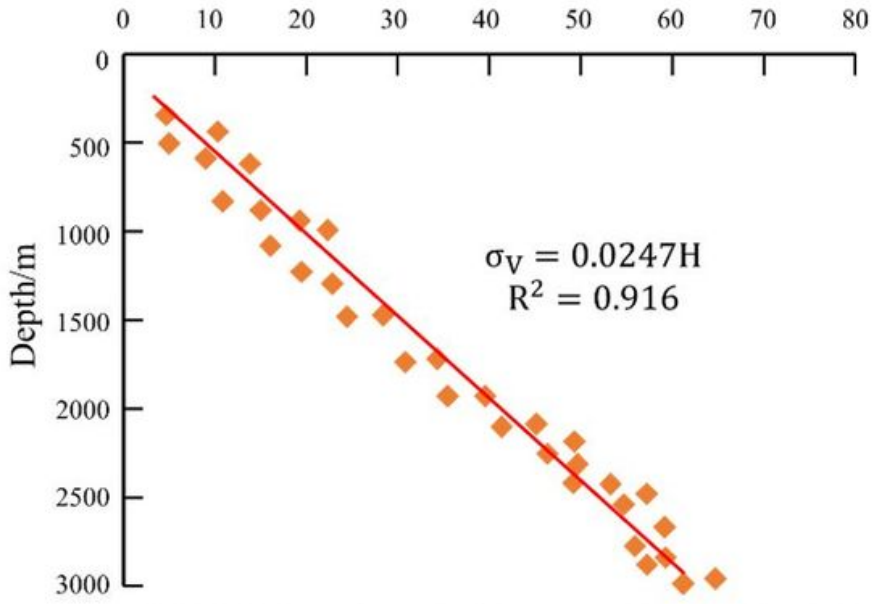

(b) Variation of vertical stress with buried depth in western Sichuan 
Figure 6

Variation of vertical stress with depth in the Sichuan Basin

Maximum horizontal principal stress/ $\mathrm{MPa}$

Maximum horizontal principal stress/ $\mathrm{MPa}$

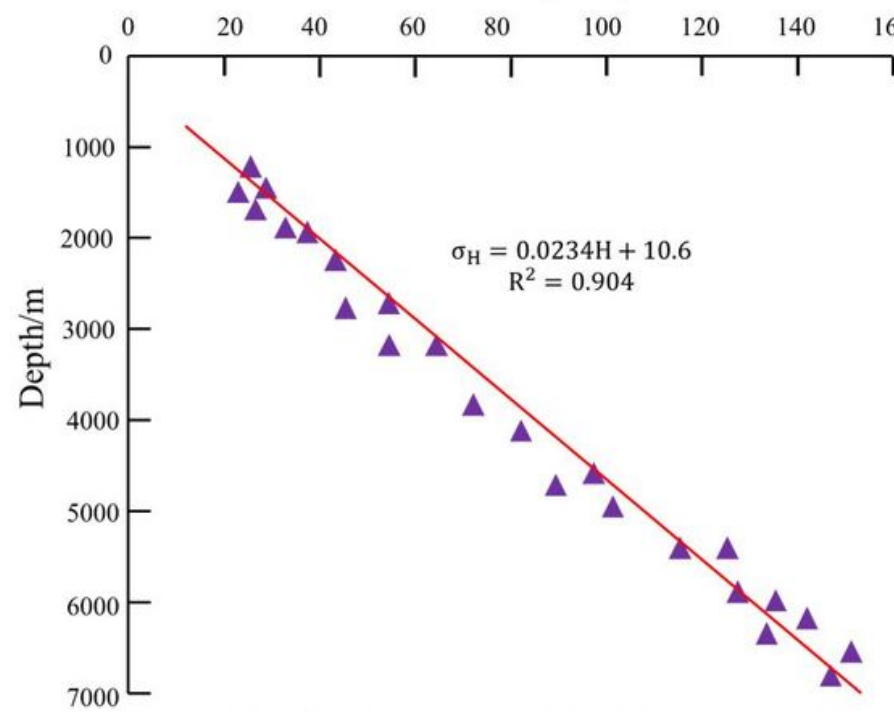

(a) Variation of Maximum Horizontal Principal Stress with Buried Depth in Northeastern Sichuan

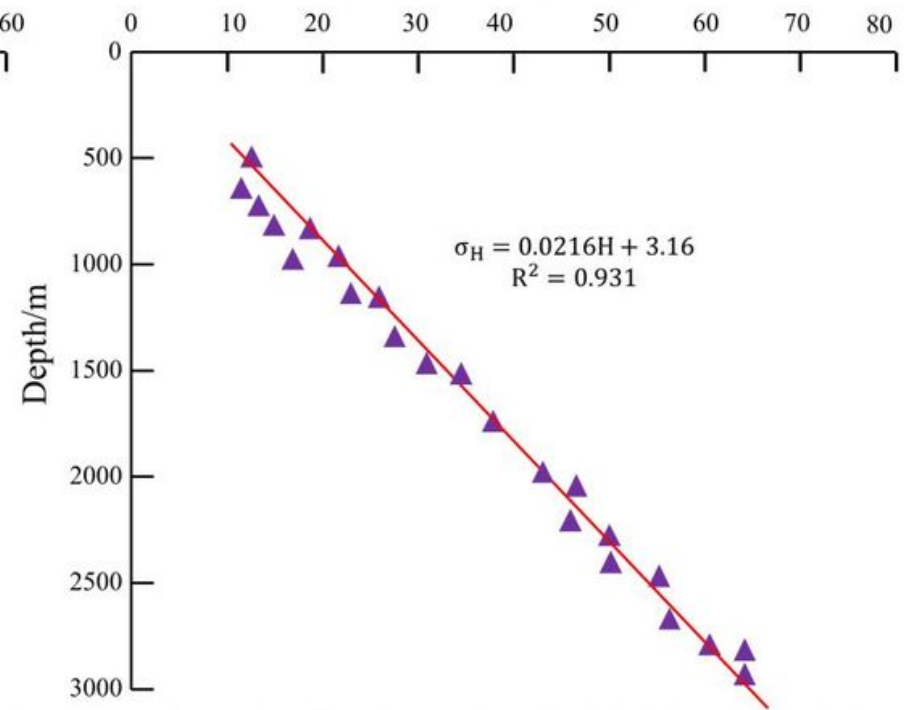

(b) Variation of Maximum Horizontal Principal Stress with Buried Depth in Western Sichuan

\section{Figure 7}

Variation of maximum horizontal principal stress with depth in the east and west of the Sichuan Basin

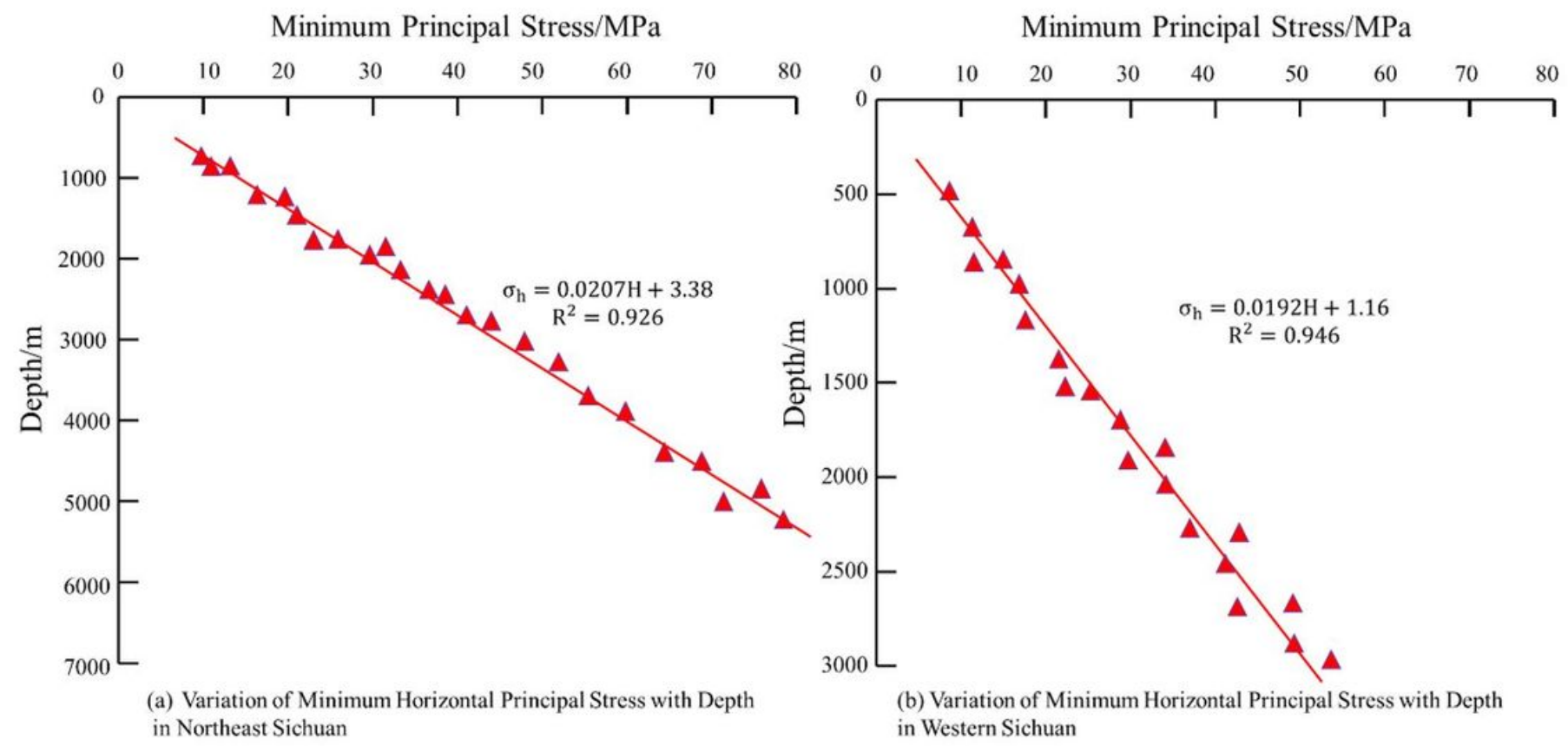

Figure 8

Variation of minimum horizontal principal stress with buried depth in the east and west of the Sichuan Basin 


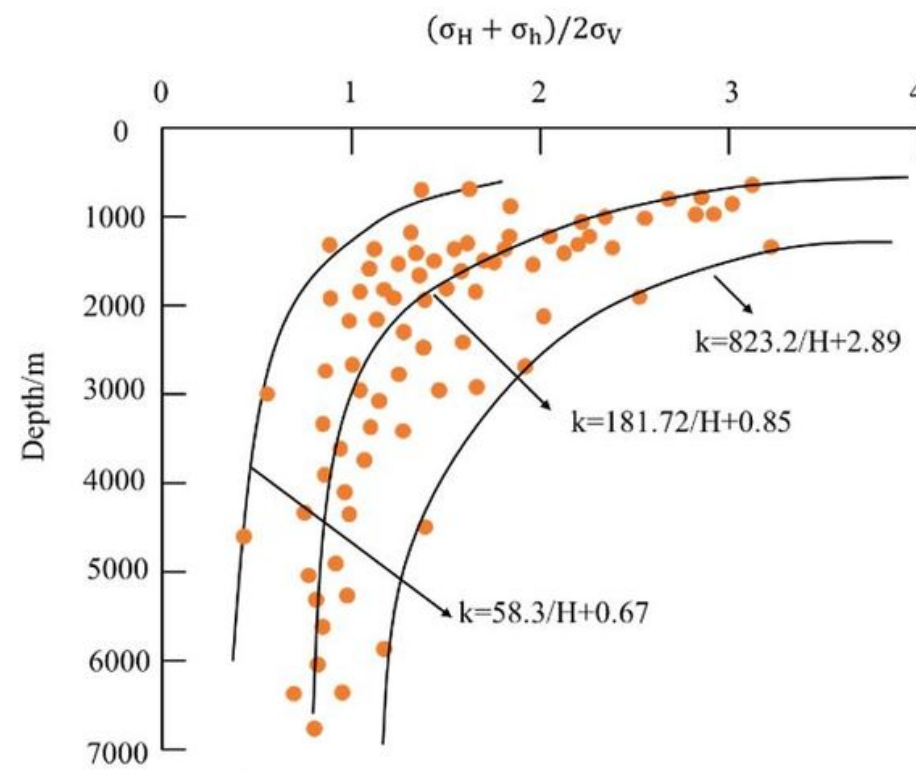

(a) The distribution of the ratio of horizontal average stress to vertical stress with buried depth in northeastern Sichuan

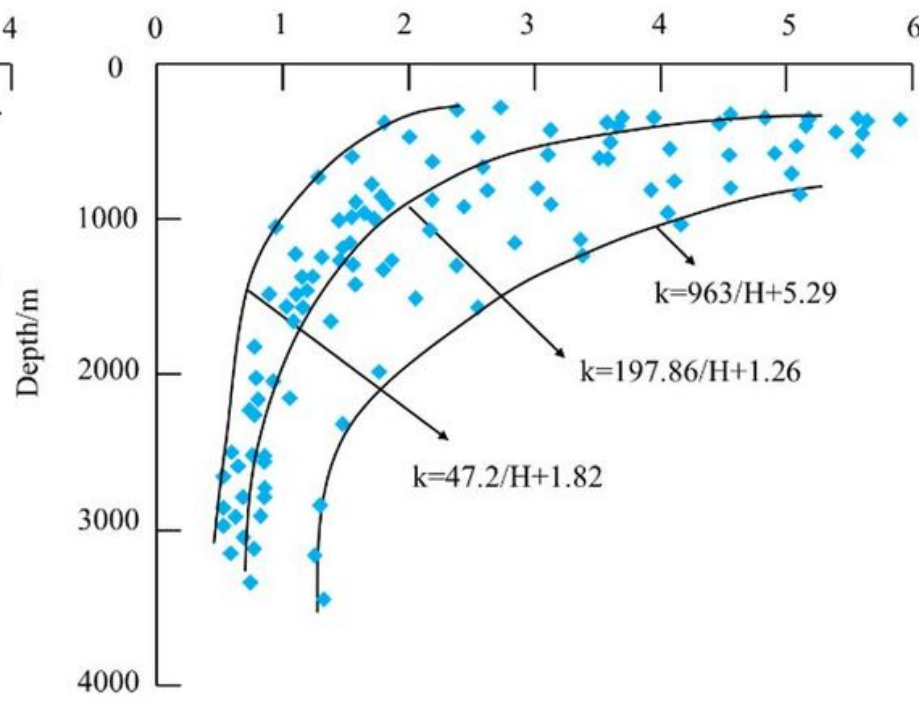

(b) The distribution of the ratio of horizontal average stress to vertical stress with buried depth in West Sichuan

\section{Figure 9}

The ratio of the horizontal average in-situ stress to the vertical stress in the eastern and western parts of the Sichuan Basin 


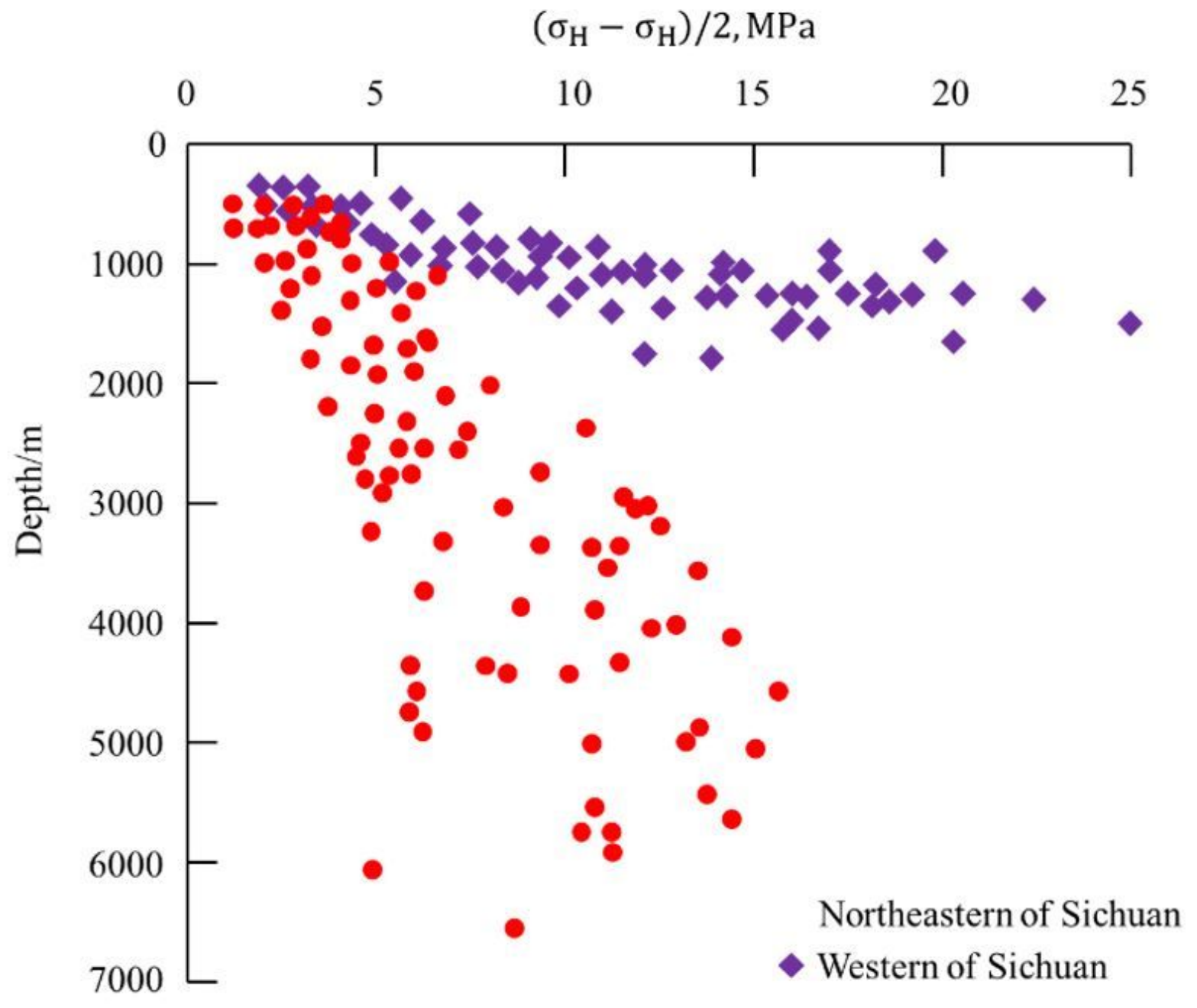

Figure 10

Distribution of horizontal shear stress with depth in northeastern Sichuan and western Sichuan 


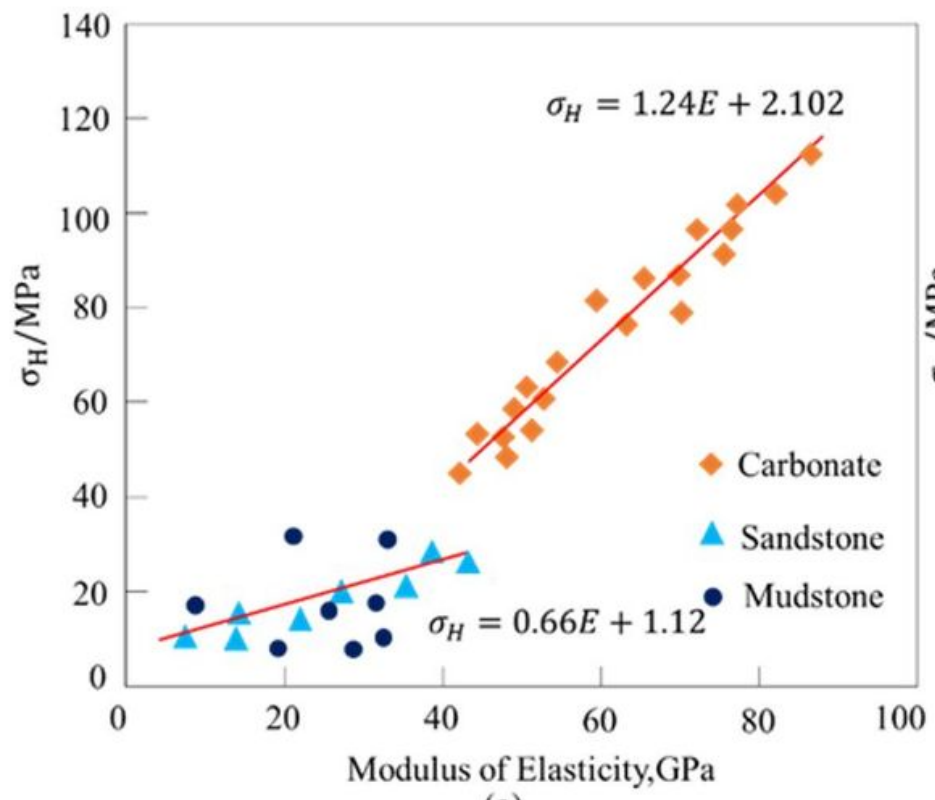

(a)

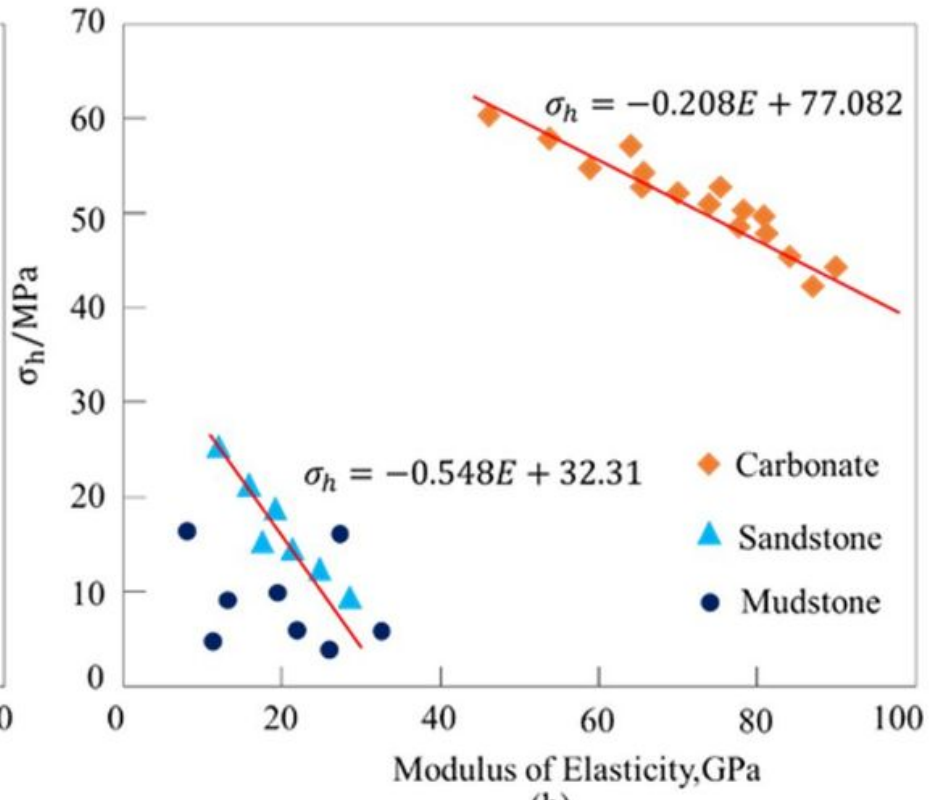

(b)

\section{Figure 11}

The relationship between elastic modulus and maximum and minimum stress

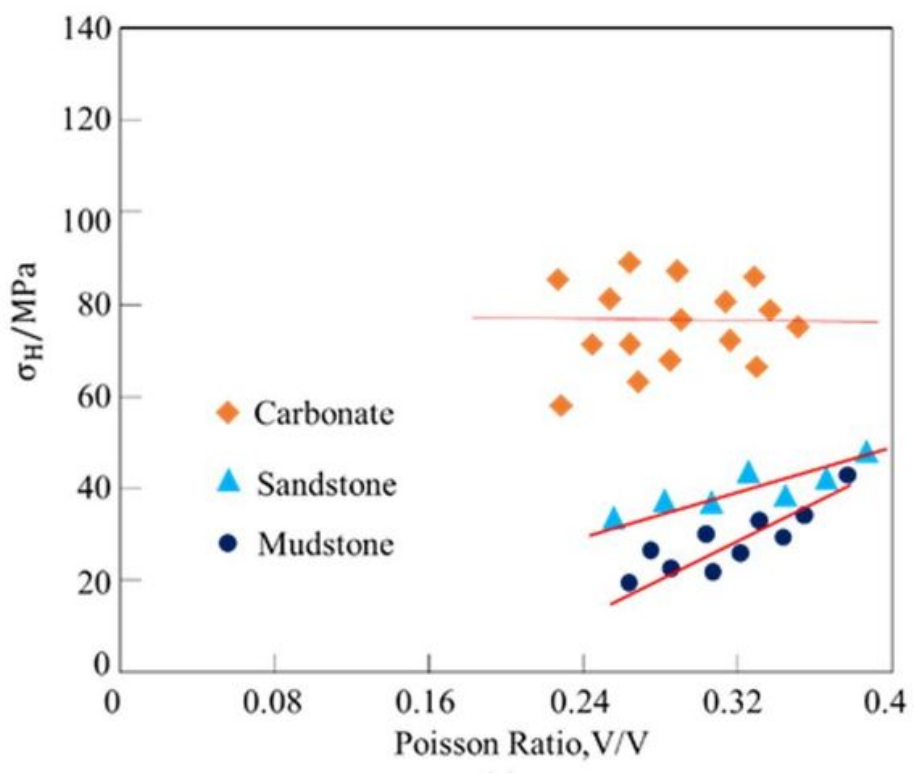

(a)

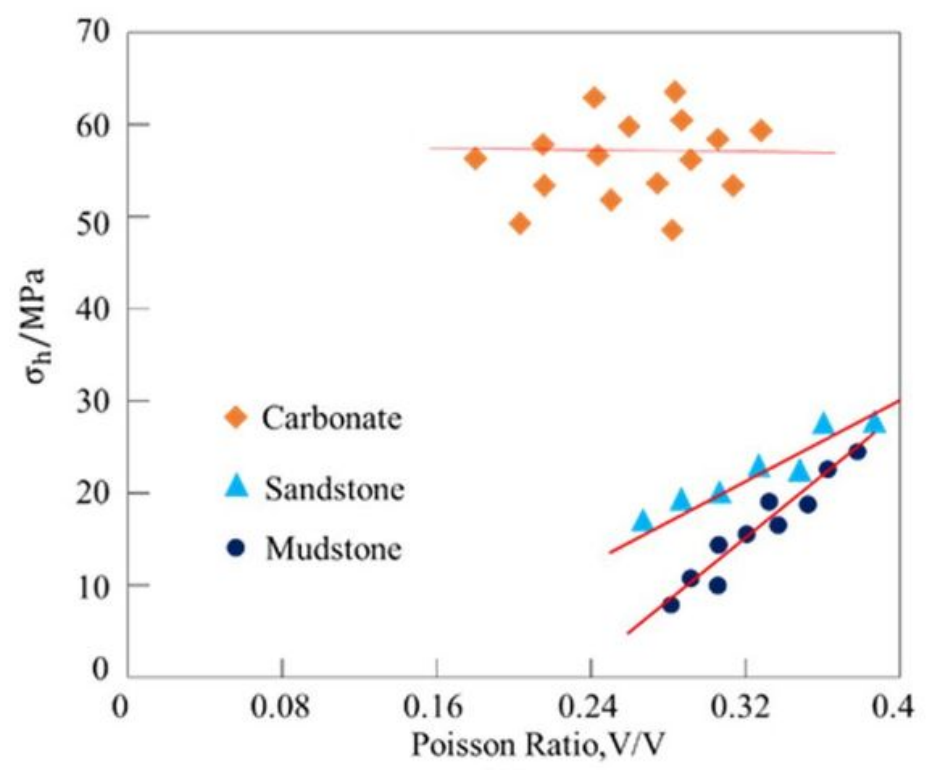

(b)

\section{Figure 12}

The relationship between Poisson's ratio and horizontal principal stress 